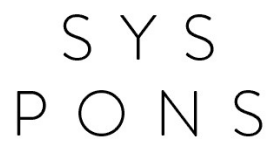

\title{
Midterm Evaluation of APPEAR II
}

Austrian Development Agency (ADA)

Final Report

September 2019 


\section{Midterm \\ Evaluation of APPEAR II}

Austrian Development Agency (ADA)

Final Report

September 2019

Syspons $\mathrm{GmbH}$

Prinzenstr. 84

10969 Berlin

(c) Syspons 2019. All rights reserved. 


\section{Contents}

List of abbreviations............................................................................ 4

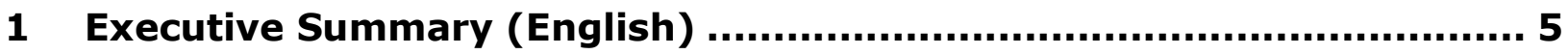

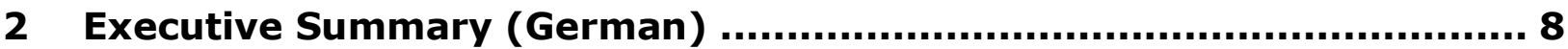

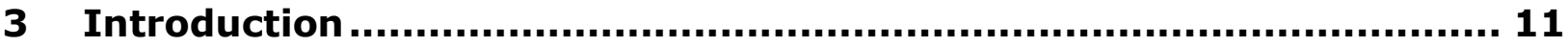

4 APPEAR programme at a glance .................................................... 12

4.1 Objectives of the APPEAR II programme and impact hypotheses.......................14

4.2 Target groups of the APPEAR II programme ............................................18

5 Scope of the evaluation and methodology........................................ 20

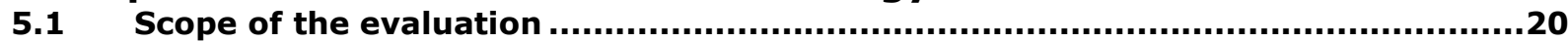

5.2 Methodological approach of the evaluation ....................................................21

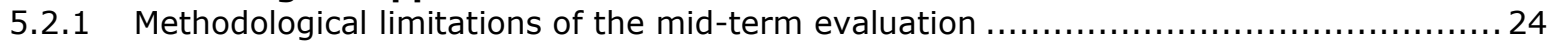

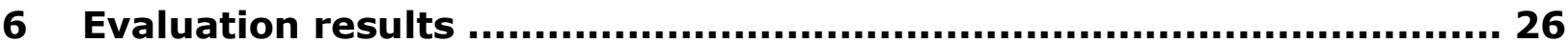

6.1 Relevance.......................................................................................................26

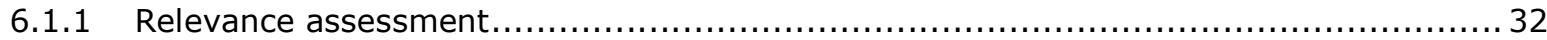

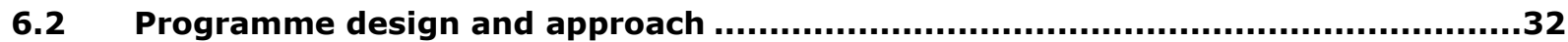

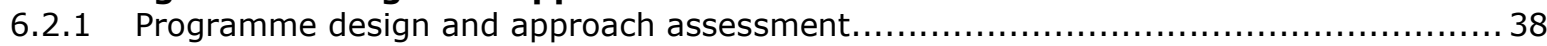

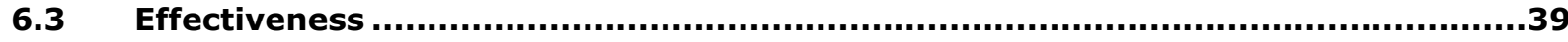

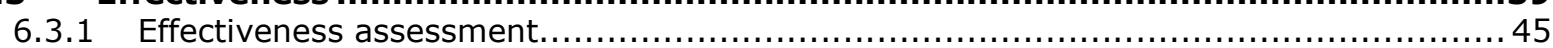

7 Conclusions ................................................................................... 46

8 Recommendations........................................................................ 48 


\section{List of abbreviations}

\begin{tabular}{|c|c|}
\hline ADA & Austrian Development Agency \\
\hline ADC & Austrian Development Cooperation \\
\hline APPEAR & Austrian Partnership Programme in Higher Education and Research \\
\hline ARES & Académie de recherche et d'enseignement supérieur \\
\hline CD & Capacity Development \\
\hline DAAD & German Academic Exchange Service \\
\hline FMEIA & Federal Ministry for Europe, Integration and Foreign Affairs (Austria) \\
\hline LAI & Austrian Latin America Institute \\
\hline MDGs & Millennial Development Goals \\
\hline OeAD & $\begin{array}{l}\text { Austrian Agency for International Mobility and Cooperation in Education, Sci- } \\
\text { ence and Research }\end{array}$ \\
\hline OECD-DAC & $\begin{array}{l}\text { Organization for Economic Co-operation and Development-Development As- } \\
\text { sistance Committee }\end{array}$ \\
\hline RACI & Responsible, Accountable, Consulted and Informed \\
\hline SDGs & Sustainable Development Goals \\
\hline ToC & Theory of Change \\
\hline VLIR & Flemish Interuniversity Council \\
\hline WUS & World University Service \\
\hline
\end{tabular}




\section{Executive Summary (English)}

\section{Background}

In 2009 the Austrian Development Agency (ADA) launched the "Austrian Partnership Programme in Higher Education and Research" (APPEAR), which represented a paradigm shift in Austrian higher education/research cooperation strategy. Before the APPEAR programme, the Austrian Development Cooperation (ADC) had traditionally allocated scholarships to members of key partner countries. However, in 2007, an evaluation of educational cooperation proposed a strategic new approach towards institutional Capacity Development (CD), instead of continued focus on individual CD (scholarships).

This strategic change was driven by the three-year Austrian Development Cooperation Policy 20082010. According to this document, there is "a need for further-reaching measures beyond assistance to individuals to involve all levels alike in scientific cooperation (management, teaching and research) [...] In future, therefore, $A D C$ will be actively supporting more comprehensive institutional cooperation between higher education institutions in partner countries and Austria" (FMEIA, 2008, p. 68). Therefore, the focus of the APPEAR programme is to strengthen institutional capacities in higher education, research and management in key regions of Austrian development cooperation.

\section{Purpose, scope and methodology of the Evaluation}

Purpose: Syspons was commissioned by ADA to carry out the mid-term evaluation of the second phase of the APPEAR programme (APPEAR II). The objective of this mid-term evaluation was to formulate recommendations, lessons learned and options for a possible third programme phase. Furthermore, the programme's theory of change was reconstructed in the framework of this mid-term evaluation.

Scope: The evaluation was carried out using the criteria relevance, programme design and approach and effectiveness, and covered the second phase of the APPEAR programme, starting in 2014. However, the evolution of the programme since its beginning was considered in the evaluation. The evaluation took place at the programme level and therefore the funded APPEAR II projects were not evaluated individually. Furthermore, the concept and implementation of the programme's basic principles and added values was also analysed in this mid-term evaluation.

Methodology: The evaluation was carried out in three phases. In the inception phase, a detailed overview of the APPEAR II Programme was obtained and all relevant analytical aspects for the mid-term evaluation were identified. Afterwards, in the collection and analysis phase a representative and comprehensive data base was built in order to answer the evaluation questions. Finally, in the reporting phase the conclusions and recommendations of the evaluation were documented.

The evaluation results stem from the analysis of documents and data (including previous evaluations), in-depth semi-structured interviews with 36 internal and external actors, an online survey of the participant institutions and a mini survey for the responsible and implementing organisations. The evaluation results were validated in a focus group with the responsible and implementing organisations.

\section{Key Findings}

One of the strengths of the APPEAR II programme is that it is highly relevant at both the international and Austrian level since it is aligned with international and Austrian frameworks/strategies in the area of (scientific) cooperation in development. Moreover, its added values and basic principles are in accordance with good practices of other donors' programmes in higher education and research. In this regard, the programme is also a pioneer in tertiary education sector cooperation as its projects should be aligned with the respective ADC country strategies, and the rights and needs of persons with disabilities should be considered in APPEAR projects.

Furthermore, the programme design and approach enable an efficient programme implementation as the OeAD uses its vast expertise in both development cooperation in the tertiary education sector and programme implementation. In particular, for the first component of the programme, the projects' 
duration of up to four years is an ideal timeframe for carrying out the Academic Partnerships. This minimum duration takes into account the fact that at the beginning of the projects, the participant institutions need time to get to know their partners and establish foundations for the partnerships. Regarding the second component, it can be concluded that the stand-alone scholarships are important for training future APPEAR applicants.

Moreover, the programme design and approach enable an effective programme implementation. In this regard, the programme design has three mechanisms to ensure that outputs and outcomes are developmentally relevant for the partner countries and their institutions. Three mechanisms ensure that APPEAR II can contribute in the long run to achieving the SDGs: i) the Preparatory Funding; ii) the application forms for Academic Partnerships and Advanced Partnerships; and iii) relevance assessment of the ADC local offices in the selection process.

At the same time, APPEAR II is effective in reaching its (intermediate) objectives as it greatly improves the teaching and research capacities of the participant institutions as well as the dialogue and cooperation between them.

Despite these strengths, the evaluation also identified some weaknesses of the APPEAR II programme. The programme's efficiency could be further improved if the ADC local offices harmonised different ADC programmes with APPEAR II projects in the partner countries in order to maximise the ADC's results. In addition, universities with little or no international experience could be connected with potential partners so that they can jointly develop and implement APPEAR projects. Although this facilitation is currently being offered by the OeAD, academic/research institutions are not using it in a systematic manner, since not all are aware of this service. Moreover, there is potential to improve the programme's efficiency since a results-oriented monitoring system could replace the current monitoring system that focuses on the activity level.

With regard to the programme's effectiveness, room for improvement exists regarding the visibility of development research issues among the wider Austrian academic/scientific public, since visibility has so far improved mainly within the APPEAR II community. Similarly, APPEAR II can further increase its effectiveness by making more improvements to the processes and structures of the participant institutions. This is important, as such structural capacity building would strengthen the partner institutions beyond the APPEAR II projects and would therefore contribute to the sustainability of the programme's effects. Lastly, the stand-alone scholarships of the programme could be more closely connected to their actual function of training future APPEAR applicants.

Alongside these weaknesses, there are also opportunities which could be used to further develop the programme. Here, the concept of "marginalized groups" could be expanded, since this concept is currently limited to persons with disabilities and women, and thus is not in line with Agenda 2030's "Leave No-one Behind" principle. Additionally, the programme could promote synergies within the APPEAR projects in order to contribute to achieving the SGDs in Austria.

In keeping with current academic discourses on gender equality, APPEAR's Gender Strategy could be broadened to reduce procedural and structural impediments for women within the APPEAR projects and the organisational structures of the partner institutions. Currently, the programme focuses solely on equal representation and promoting gender as a teaching and research topic. Similarly, the Disability Mainstreaming Manual of the programme could be better reflected in the implementation of APPEAR II projects.

Overall, it can be concluded that the APPEAR II programme has the following three unique features: i) the valuable role of partner institutions, which allows the partnerships to operate on a level playing field; ii) conceptual consideration of the rights and needs of people with disabilities, despite the implementation gap; and iii) the open access requirement. These features will enable the programme to play an important role in the field of higher education programmes in the future. 


\section{Recommendations}

The evaluation results show that APPEAR II is highly relevant and that its design and approach are efficient and effective. The results also reveal potential for further development. To make use of this potential, the evaluation derived the subsequent seven recommendations.

1. The APPEAR programme should be continued as it is highly relevant, efficient and effective. In APPEAR's third phase, the programme design and approach should maintain the instruments and mechanisms that have proved supportive of the programme's smooth implementation and its effectiveness. Furthermore, APPEAR's added values should be strengthened in order to further increase the programme's relevance.

2. In order to further improve the relevance and effectiveness of the programme, one or two new instruments should be added to the first component. These instruments should aim at improving the programme's contribution to the organisational capacities of participant institutions (processes and structures) and/or the research uptake.

3. The evaluation results show that the stand-alone scholarships contribute to the individual capacity of the scholarship holders, while APPEAR II focuses on contributing to the capacity development of the participant institutions. In order to improve the programme's coherence, it is recommended to reduce the gap between the stand-alone scholarships and the programme's rationale.

4. In order to improve APPEAR's effectiveness, the programme's monitoring system (first and second component) should be further developed into a results-oriented monitoring system.

5. APPEAR's public relations should be further developed in order for the programme to expand its target group and to further promote the achievement of the SDGs.

6. In order for APPEAR to counteract the structural and procedural obstacles to women's advancement within the higher education sector, the programme's Gender Strategy should be revised and updated.

7. In order to increase the programme's relevance, the creation of synergies is recommended between APPEAR and other ADA programmes. In this vein, analysis and discussion should focus on the extent to which the ADC local offices should connect APPEAR projects with other ADC programmes in the different partner countries. 


\section{Executive Summary (German)}

\section{Hintergrund}

Die Austrian Development Agency (ADA) führte im Jahr 2009 das „Austrian Partnership Programme in Higher Education and Research" (APPEAR) ein, womit die ADA einen Paradigmenwechsel der Österreicher Kooperationsstrategie in den Bereichen Forschung und Hochschulbildung einleitete. Vor der Einführung des APPEAR-Programms vergab die Austrian Development Cooperation (ADC) üblicherweise Stipendien an Bürger*innen aus Schlüsselpartnerländern. In einer Evaluation der Bildungskooperation 2007 wurde jedoch ein neuer strategischer Ansatz vorgeschlagen, der auf institutionelles Capacity Development $(C D)$ anstatt wie bisher auf individuelles $C D$ abzielte.

Dieser strategische Wandel wurde durch das Dreijahresprogramm der Österreichischen Entwicklungspolitik 2008-2010 angestoßen. Laut dieser Agenda existiert "ein Bedarf für weitreichendere Maßnahmen, die über die Unterstützung von Individuen hinausgeht, um alle relevanten Ebenen wissenschaftlicher Kooperationen zu involvieren (Management, Lehre, Forschung) [...] Deswegen wird die ADC in Zukunft aktiv eine umfassendere, institutionelle Kooperation zwischen österreichischen Einrichtungen tertiärer Bildung und deren Partnern in entsprechenden Ländern unterstützen." (FMEIA, 2008, S. 68). Der Fokus des APPEAR-Programms liegt deshalb darin, institutionelle Kapazitäten in der Hochschulbildung, -forschung, und dem -management in Schlüsselregionen österreichischer Entwicklungszusammenarbeit zu stärken.

\section{Zweck, Umfang und Methodologie der Evaluation}

Zweck: Syspons wurde von der ADA beauftragt, eine Zwischenevaluation der zweiten APPEAR Programmphase (APPEAR II) durchzuführen. Das Ziel dieser Evaluation war es, Empfehlungen, lessons learned, sowie Optionen für eine mögliche dritte Phase des Programms zu formulieren. Darüber hinaus wurde im Rahmen dieser Zwischenevaluation das Wirkungsgefüge des Programms rekonstruiert.

Umfang: In der Evaluation wurden die Kriterien Relevanz, Programmdesign und -ansatz sowie Effektivität betrachtet. Die Zwischenevaluation hat die zweite Phase des APPEAR-Programms geprüft, die 2014 begonnen hat. Die Entwicklung des Programms seit seinem Beginn wurde jedoch bei der Analyse berücksichtigt. Die Evaluation hat auf Programmebene stattgefunden - somit wurden die von APPEAR II geförderten Projekte nicht individuell bewertet. Darüber hinaus wurden in dieser Zwischenevaluation die Konzeption und Umsetzung der Grundprinzipien (Basic principles) und Mehrwerte (added values) des Programms analysiert.

Methodologie: Die Zwischenevaluation erfolgte in drei Phasen. In der Konzeptionsphase wurde ein detaillierter Überblick über das APPEAR II-Programm geschaffen und die relevanten, analytischen Aspekte für die Evaluation wurden identifiziert. Anschließend wurde in der Datenerhebungs- und Datenanalysephase eine repräsentative und umfassende Datengrundlage geschaffen, um die Evaluationsfragen zu beantworten. Schließlich wurden in der Berichtsphase die Schlussfolgerungen und Empfehlungen der Evaluation dokumentiert.

Die Ergebnisse der Evaluation leiten sich aus einer Analyse von Dokumenten und Daten (darunter auch vorherige Evaluationen), semi-strukturierten Tiefeninterviews mit 36 internen und externen Akteuren, einer Onlineumfrage der teilnehmende Partnerinstitutionen und einer Mini-Umfrage der verantwortlichen und durchführenden Organisationen ab. Die Evaluierungsergebnisse wurden in einer Fokusgruppe mit den verantwortlichen und durchführenden Organisationen validiert.

\section{Zentrale Erkenntnisse}

Eine Stärke des APPEAR-II-Programms ist seine hohe Relevanz sowohl auf internationaler als auch auf österreichischer Ebene. Dies ist der Fall, da das Programm mit den internationalen und österreichischen Strategien für wissenschaftliche Kooperation im Rahmen der Entwicklungszusammenarbeit im Einklang steht. Zudem decken sich die Mehrwerte und die Grundprinzipien von APPEAR-II mit guten 
Praktiken anderer Geberprogramme, die im Bereich der Hochschulbildung und Forschung implementiert werden. Verglichen mit anderen Kooperationsprogrammen ist das Programm außerdem ein Pionier im tertiären Bildungssektor, da seine Projekte mit den entsprechenden ADC Länderstrategien koordiniert sind und die Rechte und Bedürfnisse von Personen mit Behinderung berücksichtigt werden sollen.

Zudem ermöglicht das Programmdesign eine effiziente Programmimplementierung, da der Österreichischer Austauschdienst (OeAD) seine breite Expertise im Bereich der Entwicklungszusammenarbeit im tertiären Bildungssektor sowie in der Programmdurchführung nutzt. Insbesondere für die erste Komponente des Programms ist die Projektdauer von bis zu vier Jahren ideal, um die akademische Partnerschaft zu etablieren. Diese Mindestdauer berücksichtigt die Zeit, die die Partner benötigen, um sich kennen zu lernen und den Grundstein für ihre Partnerschaft zu legen. Bezüglich der zweiten Komponente ist festzustellen, dass nicht integrierte Stipendien, also Stipendien ohne Anbindung an eine Partnerschaft, wichtig sind, um zukünftige APPEAR-Bewerber zu gewinnen.

Darüber hinaus machen Programmdesign und -ansatz eine effektive Programmimplementierung möglich. In diesem Zusammenhang hat das Programm drei Mechanismen, die die entwicklungspolitische Relevanz der Programmoutputs und -outcomes für Partnerländer und ihre Institutionen sichert: i) das "Preparatory Funding"; ii) die Bewerbungsformulare für die "Academic Partnerships" and "Advanced Partnerships"; und iii) die Relevanzbewertung der lokalen ADC Büros im Auswahlprozess. Auf diese Weise wird gewährleistet, dass APPEAR II dazu fähig ist, langfristig zu den Zielen der SDGs beizutragen.

Außerdem ist APPEAR II effektiv darin, seine Zwischenziele zu erreichen. Dies ist an der Verbesserung von Lehr- und Forschungskapazitäten der teilnehmenden Institutionen sowie an dem Dialog und der Kooperation zwischen teilnehmenden Institutionen festzumachen.

Trotz dieser Stärken wurden in der Evaluation einige Schwächen des APPEAR-II-Programms identifiziert. Die Effizienz des Programms könnte noch weiter verbessert werden, indem lokale ADC Büros verschiedene ADC Programme mit APPEAR II Projekten in Partnerländern verbinden. Hierdurch könnten die Ergebnisse der ADC maximiert werden. Zudem könnte die Programmeffizienz gestärkt werden, indem akademische und/oder Forschungsinstitutionen mit wenig oder ohne internationale Erfahrung mit potenziellen Partnern in Verbindung gebracht würden, sodass diese gemeinsam APPEAR Projekte entwickeln und implementieren könnten. Obwohl eine Förderung dieser Art von der OeAD zurzeit angeboten wird, wird sie von den Institutionen nicht systematisch in Anspruch genommen, da nicht alle über diese Möglichkeit informiert sind. Zusätzlich besteht das Potential die Programmeffizienz zu verbessern, indem das derzeit verwendete Monitoringsystem, welches sich auf Aktivitäten konzentriert, durch ein wirkungsorientiertes Monitoringsystem ersetzt wird.

Bezüglich der Effektivität des Programms existiert Raum zur Verbesserung in Bezug auf die Sichtbarkeit von entwicklungsrelevanten Themen in der Forschung. Die Sichtbarkeit solcher Themen hat sich innerhalb des APPEAR-II-Programms verbessert. Zudem kann APPEAR II seine Effektivität erhöhen, indem es zu einem höheren Maße Prozesse und Strukturen in teilnehmenden Institutionen verbessert. Dies ist von Bedeutung, da der strukturelle Aufbau von Kapazitäten die Partnerinstitutionen über das APPEARII-Programm hinaus stärken würde und somit zur Nachhaltigkeit der Programmeffekte beitragen würde. Abschließend könnten die nicht integrierten Stipendien des Programms enger an ihre Funktion geknüpft werden, künftige APPEAR Bewerber zu gewinnen.

Neben diesen Schwächen existieren Chancen, die genutzt werden können, um das Programm weiterzuentwickeln. An dieser Stelle könnte das Konzept der „marginalisierten Gruppen" erweitert werden, da dieses bisher ausschließlich Frauen und Personen mit Behinderung einbezieht, und daher nicht im Einklang mit dem „leave no one behind" Prinzip der Agenda 2030 steht. Zudem könnte das Programm Synergien innerhalb der APPEAR Projekte fördern, um zur Erreichung der SDGs in Österreich beizutragen.

Zusätzlich könnte die Gender-Strategie von APPEAR erweitert werden und damit prozessuale und strukturelle Hemmnisse für Frauen innerhalb der APPEAR Projekte und Organisationsstruktur von Partnerinstitutionen abzubauen, um im Einklang mit dem aktuellen akademischen Diskurs zu Gleichstellung der 
Geschlechter zu stehen. Aktuell ist das Programm hauptsächlich auf Frauenquoten in den APPEAR-Projekten und die Förderung von Gender als Forschungs- und Lehrthema fokussiert. Gleichermaßen könnte das Disability Mainstreaming Manual des Programms stärker in der Durchführung von APPEAR-Projekten reflektiert sein.

Insgesamt lässt sich schlussfolgern, dass das APPEAR-II-Programm die folgenden drei Alleinstellungsmerkmale besitzt: i) die wertvolle Rolle von Partnerinstitutionen, welche eine gleichwertige Zusammenarbeit zwischen den beteiligten Institutionen erlaubt; ii) die Rechte und Bedürfnisse von Personen mit Behinderung wird konzeptionell in Betracht gezogen - trotz Lücken in der Durchführung; und iii) die Bedingung des freien Zugangs („open Access"). Diese Eigenschaften werden dem Programm erlauben, auch in Zukunft eine wichtige Rolle im Bereich der Hochschulprogramme zu spielen.

\section{Empfehlungen}

Die Evaluationsergebnisse zeigen, dass APPEAR II hoch relevant ist und dass das Design und der Ansatz des Programms effektiv und effizient sind. Die Ergebnisse decken außerdem das Potential für die zukünftige Entwicklung des Programms auf. Um dieses Potential zu nutzen, wurden aus der Evaluation die folgenden sieben Empfehlungen gezogen.

1. Das APPEAR-Programm sollte fortgesetzt werden, da es hochgradig relevant, effizient und effektiv ist. Das Programmdesign und der Ansatz der dritten APPEAR-Phase sollten diejenigen Mechanismen und Instrumente beibehalten, die sich für die reibungslose und effektive Umsetzung bewährt haben. Darüber hinaus sollten die "Added Values" von APPEAR gestärkt werden, um die Relevanz des Programms weiter zu erhöhen.

2. Um Relevanz und Effektivität des Programms weiter zu verbessern, sollten der ersten Komponente ein oder zwei neue Instrumente hinzugefügt werden. Diese sollten darauf abzielen, die Beiträge des Programms zu den organisationalen Kapazitäten der Partnerinstitutionen und/oder das "Research Uptake" zu befördern.

3. Die Evaluierungsergebnisse zeigen, dass die nicht integrierten Stipendien zu den individuellen Kapazitäten der Stipendiat/innen beitragen, während APPEAR-II sich auf das Capacity Development der teilnehmenden Partnerinstitutionen konzentriert. Um die Kohärenz des Programms zu stärken, wird empfohlen, die Lücke zwischen den nicht integrierten Stipendien und der Logik des Programms zu verringern.

4. Um die Effektivität von APPEAR zu verbessern sollte das Monitoringsystem für die Komponenten eins und zwei in ein wirkungsorientiertes Monitoring weiterentwickelt werden

5. Die Öffentlichkeitsarbeit von APPEAR sollte weiter ausgebaut werden, um die Zielgruppe zu erweitern und den Beitrag zu den SDGs weiter zu bewerben.

6. Um den strukturellen und prozessualen Hindernissen für Frauen im Hochschulsektor zu begegnen, sollte die Gender-Strategie des Programms überarbeitet werden.

7. Um die Relevanz des Programms zu erhöhen empfiehlt sich die Entwicklung von Synergien zwischen APPEAR und anderen ADA-Programmen. Hierbei sollte der Fokus auf der Analyse und Diskussion liegen, inwieweit die jeweiligen lokalen ADC-Büros die APPEAR-Projekte mit anderen ADC-Programmen in den verschiedenen Partnerländern verbinden können. 


\section{Introduction}

Syspons was commissioned by the Austrian Development Agency (ADA) to carry out the mid-term evaluation of the "Austrian Partnership Programme in Higher Education and Research II" (APPEAR II). APPEAR II aims to strengthen institutional capacities in the field of higher education, research and management in key regions of Austrian development cooperation. The aim of this mid-term evaluation is to formulate recommendations, lessons learned and options for a possible third programme phase.

The evaluation is carried out using the criteria relevance, programme design and approach and effectiveness. It covers the second phase of the APPEAR programme, starting in 2014. Furthermore, the evaluation takes place at the programme level, therefore the funded APPEAR II projects will not be evaluated individually.

In this evaluation, Syspons presents the following Final Report in which the main findings of the evaluation and the resulting recommendations are described and explained. Therefore, the Final Report is structured as follows:

- Chapter 4 presents a description of the APPEAR II programme, including its objectives and relevant actors.

- Chapter 5 outlines the methodological approach of the evaluation and its limitations.

- Chapter 6 contains the evaluation results structured according to the three evaluation criteria, namely i) relevance, ii) programme design and approach and iii) effectiveness.

- Chapter 7 presents the evaluation conclusions.

- Chapter 8 outlines the evaluation recommendations.

- The Annex includes the list of interviewed persons in the data collection phase, the evaluation assessment grid and the bibliography. 


\section{APPEAR programme at a glance}

The Austrian Development Agency (ADA) launched the APPEAR programme in 2009, which represented a paradigm change in Austrian higher education/research cooperation strategy. Before the APPEAR programme, the Austrian Development Cooperation (ADC) had traditionally allocated scholarships to members of key partner countries. However, in 2007, an evaluation of educational cooperation proposed a strategical new approach towards institutional Capacity Development (CD), instead of continued focus on individual CD (scholarships).

This strategical change was driven by the three-year programme of the Austrian Development Cooperation Policy 2008-2010. According to this document, there is "a need for further-reaching measures beyond assistance to individuals to involve all levels alike in scientific cooperation (management, teaching and research) [...] In future, therefore, ADC will be actively supporting more comprehensive institutional cooperation between higher education institutions in partner countries and Austria" (FMEIA, 2008, p. 68).

Therefore, the focus of the APPEAR programme is to foster institutional partnerships between higher education/research institutions. However, the ADC continues using scholarships to a lesser extent and therefore, they are still being allocated within the programme until today. These scholarships are either embedded in existing institutional partnerships, or are stand-alone scholarships. Against this background, the programme has various instruments distributed between two components.

\section{First component}

In this component, the APPEAR II programme fosters partnerships between higher education and/or research institutions in Austria and the partner countries. In order to establish and consolidate these partnerships, the programme has three instruments (APPEAR, 2017c).

1. First, Academic Partnerships between the aforementioned institutions are funded in order to strengthen their capacities in teaching, research and/or management.

2. Additionally, Advanced Academic Partnerships are also promoted. These partnerships are based on the results of successfully finalised Academic Partnerships and should develop innovative cooperation designs.

3. Furthermore, the Preparatory Funding aims at setting up new partnerships between the aforementioned institutions. This funding is provided for the institutions to elaborate realistic project proposals, based on their demands and needs. Only new partnerships are eligible for this type of funding.

\section{Second component}

This component is primarily intended to provide scholarships to Masters and $\mathrm{PhD}$ students from universities in partner countries who are involved in the first component and who, due to their studies, can contribute to an ongoing Academic Partnership or an Advanced Academic Partnership (APPEAR, 2014). However, a given amount of scholarships is also allocated outside of these partnerships. The percentage of Masters/PhD students embedded in a partnership is around $75 \%$ of the total number of APPEAR II scholarships. 
For the implementation of the APPEAR II programme, ADA has decided that both programme components should continue to be guided by five basic principles ${ }^{1}$ (APPEAR, 2014). These principles reflect the unique features of the programme and are meant to foster eye-to-eye partnerships. The basic principles are:

1. Participatory approach: according to this principle, there must be a lived partnership in the design and implementation of the projects. Furthermore, there must be a fair distribution of funds, of which at least $50 \%$ should be implemented in the partner countries.

2. Culturally open-minded knowledge: in order to implement this principle, there must be respect for other cultural, epistemological, methodological and empirical approaches during the generation of knowledge. In particular, "one-sided knowledge transfer" should be avoided within the partnerships.

3. Empirical-oriented approach: the programme must foster results-oriented research and teaching. Only this way can the research/teaching results be used in order to promote development in the partner countries.

4. Gender-sensitivity: in the projects, equality between men and women must be fostered, as well as the research of gender-relevant topics.

5. Bottom-up and demand-driven approach: moreover, the essential contents of the supported projects must be determined by the institutions in the partner countries, in coordination with the thematic APPEAR priorities.

Furthermore, APPEAR II has defined added values that are not obligatory for a project to be selected, but if they are fulfilled, the project proposal will receive a better assessment. In this vein, the APPEAR II programme has the following added values: first, the projects should be aligned with the respective ADC country strategy. Second, the APPEAR partnerships should consider the rights and needs of persons with disabilities in their project work. Third, regional networks should be fostered within the framework of the programme. And fourth, there should be a focus on young scientists and, particularly, on young female scientists.

Considering the programme characteristics mentioned above, the APPEAR II programme has adapted its thematic and geographical emphasis according to the prevailing ADC strategy (see the threeyear programmes of the Austrian Development Policy). For the second phase of the programme, the following thematic emphases are being fostered within the framework of the partnerships:

- water supply and sanitation

- rural development

- sustainable energy

- environment and natural resources

- private sector development

- poverty reduction

- peace building and conflict prevention

- governance and human rights

- gender equality

- strengthening skills in social sciences as an instrument to systematically analyse the reasons for poverty and to empower capacities in social science research (APPEAR, 2017c).

Regarding the geographical emphasis of the programme, institutions/persons from the following countries are currently eligible to participate in the programme: Ethiopia, Uganda, Kenya, Mozambique,

\footnotetext{
${ }^{1}$ The five basic principles were already implemented in the first phase of the APPEAR programme.
} 
Cape Verde, Burkina Faso, Senegal, Nicaragua, El Salvador, Guatemala, Bhutan, Nepal, Palestine, Georgia, Armenia and the Republic of Moldova, henceforth partner countries (for more details, see chapter 2.2).

As mentioned before, this mid-term evaluation focuses on the second phase of the APPEAR programme which began in 2014 and will be implemented until 2020. During these years, the programme has implemented the fifth, sixth and seventh calls for applications. Furthermore, the programme budget for the second phase is 12 Million Euro. Approximately $75 \%$ of the financial resources are planned to be invested in the first component while $25 \%$ in the second component (APPEAR, 2014).

\subsection{Objectives of the APPEAR II programme and impact hypotheses}

To achieve a common understanding of the APPEAR II programme objectives, a Theory of Change (ToC) has been developed for the programme. The ToC was presented and discussed in a workshop at which staff members of ADA, the Federal Ministry for Europe, Integration and Foreign Affairs (FMEIA) and the Austrian Agency for International Mobility and Cooperation in Education, Science and Research (OeAD) participated. The adjusted version of the ToC was subsequently sent by email and further adjusted according to the feedback received from these three organisations. The last version of the ToC is presented below. This ToC serves as a basis for this evaluation and consists of different inter-connected and independent components. The different levels of the $\mathrm{ToC}$ are defined as following:

- Inputs / activities: "the financial, human, and material resources used for the development intervention" (defined according to the OECD-DAC, 2010, p. 25)

- Outputs: "the products, capital goods and services which result from a development intervention" (Ibid., p. 28)

- Outcomes: "the likely or achieved short-term and medium-term effects of an intervention's outputs." (Ibid., p. 28)

- Impacts: "positive and negative, primary and secondary long-term effects produced by a development intervention, directly or indirectly, intended or unintended" (Ibid., p. 24)

In the following, the ToC of the APPEAR II programme is presented. The term "participant institutions" refers to both Austrian institutions and institutions in the partner countries, while the term "partner institutions" alludes only to the partner countries' institutions. 
Figure 1: Theory of Change of the APPEAR II programme

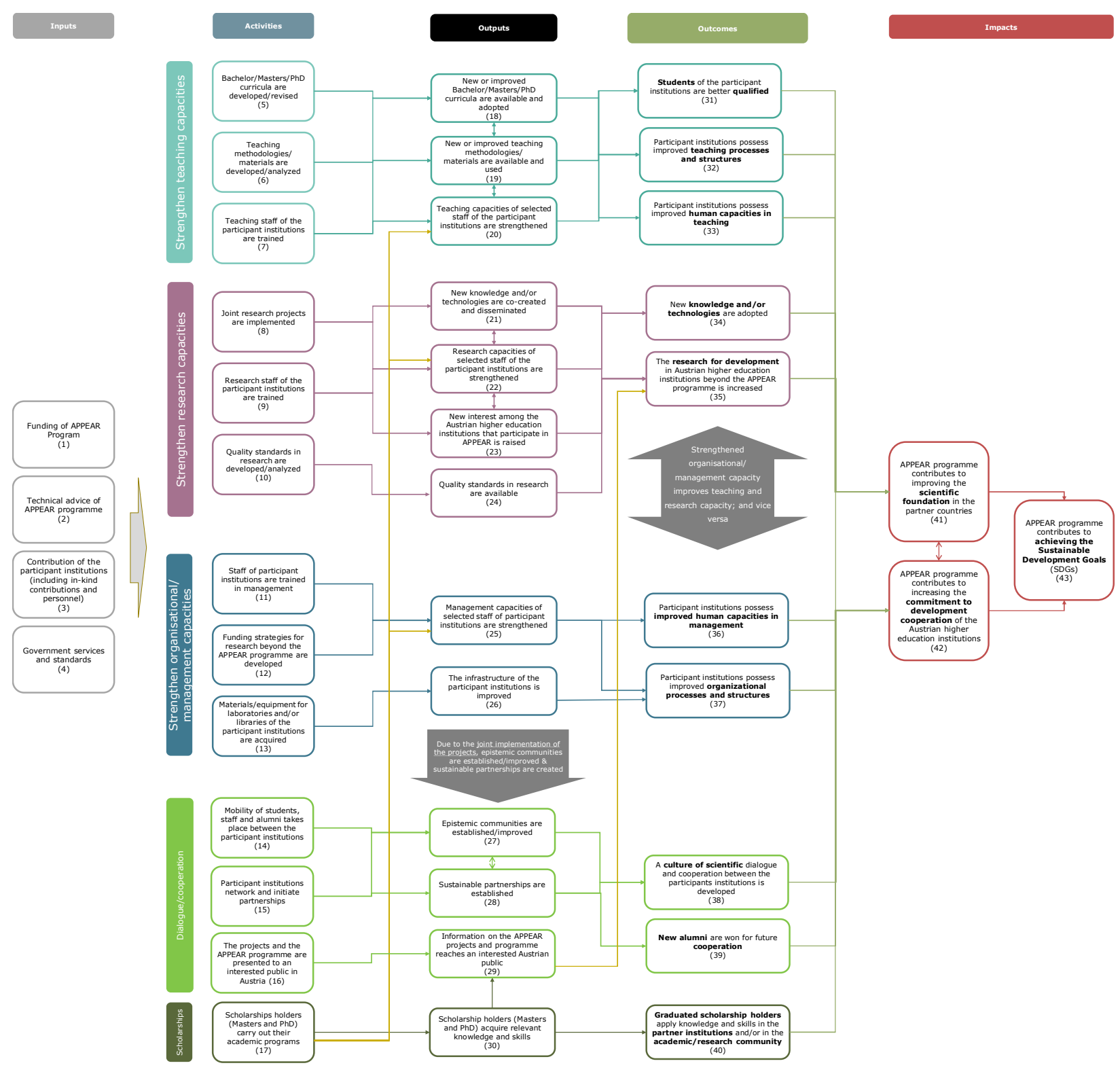


At the impact level, the objective of the APPEAR II programme is to contribute to achieving the Sustainable Development Goals (SDGs). Even if the second phase of the programme was launched shortly before the SDGs were agreed upon (and when the Millennial Development Goals were the guiding international framework), the reconstruction of the programme Theory of Change indicated that the programme should contribute to the SDGs. In order to achieve this goal, the programme should achieve its main long-term objectives, namely contribute to improve the scientific foundation in the partner countries as well as to increase the commitment to development cooperation of Austrian higher education institutions.

In order to achieve these long-term impacts, the APPEAR II programme has different objectives at the outcome level, which are respectively supported by the programme outputs. These outcomes and outputs are categorised in the following five impact strands.

\section{Strengthening of teaching capacities}

Outcome 1: Students of the partner institutions are better qualified:

- if new or improved Bachelors/Masters/PhD curricula are available and adopted (impact hypothesis 1).

- if new or improved teaching methodologies/materials are available and used (impact hypothesis 2).

- if the teaching capacities of selected staff at the participant institutions are strengthened (impact hypothesis 3).

Outcome 2: Partner institutions possess improved teaching processes and structures:

- if new or improved Bachelors/Masters/PhD curricula are available and adopted (impact hypothesis 4).

- if new or improved teaching methodologies/materials are available and used (impact hypothesis 5).

- if the teaching capacities of selected staff of the participant institutions are strengthened (impact hypothesis 6).

Outcome 3: Partner institutions possess improved human capacities in teaching:

- if new or improved Bachelors/Masters/PhD curricula are available and adopted (impact hypothesis 7).

- if new or improved teaching methodologies/materials are available and used (impact hypothesis 8 ).

- if the teaching capacities of selected staff of the participant institutions are strengthened (impact hypothesis 9).

\section{Strengthening of research capacities}

Outcome 4: New knowledge and/or technologies are adopted:

- if they are previously co-created and disseminated (impact hypothesis 10). 
- if the research capacities of selected staff at the partner institutions are strengthened (impact hypothesis 11).

- if new interest is raised among Austrian higher education institutions participating in APPEAR II (impact hypothesis 12).

- if new or improved quality standards are available (impact hypothesis 13 ).

Outcome 5: The research for development in Austrian higher education institutions beyond the APPEAR II programme is increased:

- if new knowledge and/or technologies are co-created and disseminated (impact hypothesis 14).

- if the research capacities of selected staff of the partner institutions are strengthened (impact hypothesis 15).

- if new interest is raised among Austrian higher education institutions participating in APPEAR II (impact hypothesis 16).

- if new or improved quality standards are available (impact hypothesis 17 ).

- if information on the APPEAR II projects and programme reaches an interested public in Austria (impact hypothesis 18).

\section{Strengthening of organisational/management capacities}

Outcome 6: Partner institutions possess improved human capacities in management:

- if the management capacities of selected staff at partner institutions are strengthened (impact hypothesis 19).

Outcome 7: Partner institutions possess improved organizational processes and structures:

- if the management capacities of selected staff at partner institutions are strengthened (impact hypothesis 20 ).

- if the infrastructure of the partner institutions is improved (impact hypothesis 21 ).

\section{Dialog / cooperation}

Outcome 8: A culture of scientific dialogue and cooperation between the participants institutions is developed:

- if epistemic communities are established/improved (impact hypothesis 22),

- if sustainable partnerships are established (impact hypothesis 23 ).

Outcome 9: New alumni are won for future cooperation:

- if epistemic communities are established/improved (impact hypothesis 24).

- if sustainable partnerships are established (impact hypothesis 25). 
Outcome 10: Graduate scholarship holders apply knowledge and skills in the partner institutions and/or in the academic/research community:

- if scholarship holders (Masters and PhDs) have previously acquired relevant knowledge and skills (impact hypothesis 26).

Furthermore, there are two general assumptions at the outcome and output level (see grey arrows in the ToC). At the outcome level, it is assumed that strengthened organisational/management capacity improves teaching and research capacity and vice versa. At the output level, it is assumed that due to the joint implementation of the projects, epistemic communities are established/improved and sustainable partnerships are created.

In order to materialize the aforementioned impact hypotheses, the ToC foresees several activities. In order to strengthen teaching capacities, Bachelors/Masters/PhD curricula are developed/revised, teaching methodologies/materials are developed/analysed, and teaching staff at partner institutions are trained. In order to strengthen research capacities, joint research projects are implemented, research staff at partner institutions are trained, and quality standards in research are developed/analysed. Moreover, with the aim of strengthening organisational/management capacities, staff at partner institutions are trained in management, funding strategies for research beyond the APPEAR II programme are developed, and materials/equipment for laboratories and/or libraries of the partner institutions are acquired.

Furthermore, to improve the dialogue and cooperation between the participant institutions, mobility of students, staff and alumni takes place, networks and partnerships are initiated and APPEAR II (its projects and the programme) is presented to an interested public in Austria. Finally, regarding the scholarships (second component), scholarship holders (Masters and PhDs) carry out their academic work.

The inputs necessary to carry out APPEAR II are the funding and technical advice of the programme, the contributions of the participant institutions (including in-kind contributions and personnel), as well as government services and standards.

\subsection{Target groups of the APPEAR II programme}

The evaluation differentiates between responsible and implementing organisations, as well as target groups of the APPEAR II programme. These categories are defined in the following manner:

- Responsible organisations are the organisations that have institutional responsibility for the programme.

- The implementing organisations are responsible for the execution of the programme. They are responsible for the achievement of the programme objectives.

- The target group is defined as those actors who should benefit from the APPEAR II programme in terms of its intended objectives and impacts.

For the purpose of this evaluation, the following organisations/persons assume the following roles:

- The FMEIA and ADA are the responsible organisations for the APPEAR II programme. On the one hand, the FMEIA is responsible for providing the strategic direction of the programme, since it issues the three-year programmes as well as the relevant strategic documents in the area of higher education and capacity development for the ADC. Moreover, the FMEIA is responsible for financing the programme. 
On the other hand, ADA is responsible for recruiting, contracting and supervising the organisation that implements the programme. ADA assures that the implementing organisation effectively fulfils its contractual obligations and implements the programme according to the Terms of Reference. ADA is therefore responsible to the FMEIA for the appropriate implementation of the programme.

- The OeAD is the implementing organisation of the APPEAR II programme. It implements both the first and second programme components. Furthermore, it has implemented the first and second phase of the programme, since it has won both tenders.

At the beginning of APPEAR II, there were two additional implementing organisations that acted as subcontractors of the OeAD and who had specific roles while setting up the second programme phase. The World University Service (WUS) was in charge of providing advice during the application process to higher education/research institutions from Armenia, Georgia and Moldova. Furthermore, WUS provided the needed regional expertise and access to networks in the aforementioned countries. In a similar way, the Austrian Latin America Institute (LAI) was supposed to contribute with its expertise in Nicaragua, El Salvador and Guatemala. However, the cooperation between the LAI and OeAD was finished after one and a half year, due to contractual differences. Currently, the OeAD is the only implementing organisation.

- Regarding the target groups of the programme, these need to be differentiated for both components:

- In the first component, the target group is the staff of higher education and/or research institutions in Austria and the following partner countries: Ethiopia, Uganda, Kenya, Mozambique, Cape Verde, Burkina Faso, Senegal, Nicaragua, El Salvador, Guatemala, Bhutan, Nepal, Palestine, Georgia, Armenia and the Republic of Moldova. Nevertheless, it is possible for institutions of third countries (in the partner regions) to participate in regional partnerships as long as they implement less than $20 \%$ of the total project budget. In addition, it is possible to incorporate European institutions in the partnerships under certain conditions. ${ }^{2}$

- In the second component, a differentiation has to be made between the scholarships that are embedded in a partnership and those that are not. For the former, the candidates can come in exceptional cases from countries other than those listed above, as long as the Masters/PhD studies significantly support the achievement of the project objectives. For the latter, the scholarship holders must come exclusively from the aforementioned countries.

${ }^{2}$ In order for European institutions to participate in a partnership, the following conditions must be met:

- The European partners cannnot receive any funding from the APPEAR partnership.

- The European partners cannnot coordinate the project.

- The work or research contribution of the European partner must be less than the contribution of the Austrian and southern partners.

- The APPEAR project cannot be part of a larger project that influences the characteristics of the APPEAR project

- $\quad$ The ADC must be visible. (APPEAR, 2014) 


\section{Scope of the evaluation and methodology}

\subsection{Scope of the evaluation}

This mid-term evaluation focused on the programme level and assessed the second phase of the APPEAR programme. Three main evaluation criteria were used in the mid-term evaluation: i) relevance, ii) programme design and approach and iii) effectiveness.

\section{Relevance}

The relevance of the programme was assessed focusing on three main areas. Firstly, the international relevance of the programme was evaluated. For this, the evaluation team examined whether the programme is in line with international strategies/frameworks and whether the programme concept is relevant in the context of the current international debate on scientific cooperation in development. Furthermore, the evaluation analysed to what extent the programme considers the reciprocal relation between higher education / research and poverty reduction. Second, the evaluation focused on examining the relevance for the Austrian Development Cooperation Policy. For this, the consistency between the programme and the ADC strategies was analysed. And thirdly, the coherence of the APPEAR II programme with the ADA portfolio in the area of higher education / research was studied.

\section{Programme design and approach}

The mid-term evaluation focused on analysing to what extent the programme's concept allows an efficient and effective programme implementation. In regard to the effective implementation, the evaluation team focused on examining the plausibility of the impact pathway. Regarding the efficient implementation, the evaluation focused on analysing in detail the project design and approach. For this, the functioning of the first and second programme components, as also the interlinkages between them, was assessed. Furthermore, it was examined whether the programme design and approach correspond to the needs of the partner countries and participant institutions.

Furthermore, the evaluation team assessed the efficiency of APPEAR II by operationalising the RACImethod in combination with a perception analysis. RACI (Responsible, Accountable, Consulted and Informed) is an acronym derived from the four main roles that are key to efficient programme management. Through these roles, the responsibilities of stakeholders (responsible organisations, implementing organisations and target groups) are clarified and communicated at any stage of the programme. Thereby, it allows for checking potential sources of (in)efficiency, e.g. minimising the risk of responsibility gaps, overlaps, duplications, and confusions regarding responsibility, accountability, consultation and information in a programme and project activity.

To carry out the perception analysis, we integrated scales based upon semantic differentials into the online survey for the participant institutions and the mini online survey for responsible and implementing organisations. Using the collected data, the evaluation team was able to juxtapose the perceptions of internal and external stakeholders and draw analytical insights into the programme's efficiency from this comparison.

\section{Effectiveness}

The effectiveness of APPEAR II was assessed by focusing on two main areas of interest. In a first step, the achievement of the programme outcomes (see Theory of Change) was analysed. In particular, it was examined how the modality of the programme execution (commissioning of a third party) influences the achievement of the programme results. Furthermore, context factors that have a positive or negative influence on the achievement of programme results were scrutinized. In a next step, the evaluation team focused on assessing the implementation of the programme strategies and guiding documents.

For further details regarding the evaluation scope, please see the evaluation assessment grid in the annex. 


\subsection{Methodological approach of the evaluation}

In order to carry out the evaluation, Syspons and ADA agreed a methodological approach that is described in detail in the Inception Report. Accordingly, the evaluation consists of the following three phases:

Figure 2: Evaluation design

\section{Phase 1 - Inception Phase}

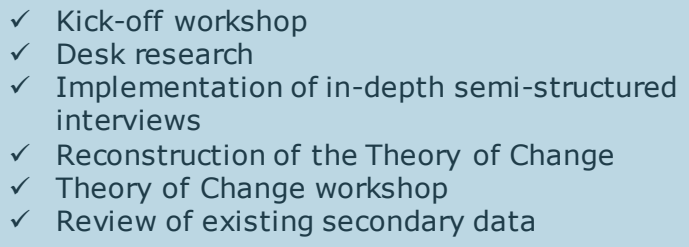

Phase 2 - Collection and Analysis Phase
Interviews
$\begin{aligned} & \text { Online survey for participant } \\ & \text { institutions }\end{aligned}$ $\begin{gathered}\begin{array}{c}\text { Mini online survey for } \\ \text { responsible and implementing } \\ \text { organisations }\end{array} \\ \begin{array}{l}\text { Implementation of 30-35 } \\ \text { semi-structured Individual } \\ \text { and Group Interviews } \\ \text { questionnaire for the survey } \\ \text { and implementation of the } \\ \text { survey } \\ \checkmark \text { Analysis of the survey results }\end{array}\end{gathered}$

\section{Inception phase}

The objective of the inception phase was to obtain a detailed overview of the APPEAR II Programme and to identify all relevant analytical aspects for the mid-term evaluation. In order to implement an effective and efficient mid-term evaluation, it was essential to first establish a common understanding of the mid-term evaluation and to agree upon a sound process architecture. This was one of the main goals of the kick-off workshop with ADA, FMEIA and OeAD, conducted by Syspons.

The starting point of the mid-term evaluation was a desk research of key documents. Through this desk research, we gained a thorough understanding of the subject and built the foundation for the following analytical steps. Thus, the desk research had multiple objectives: on the one hand, it situated the APPEAR II Programme in the wider analytical context of existing international strategies, current reference frameworks and strategies of the ADC. On the other, it delivered a first description of the 
content, objectives and processes of the programme. In order to implement the desk research, we developed a preliminary assessment grid according to the evaluation questions raised in the Terms of Reference to systematically analyse the documents. It served as a basis for the development of the final evaluation assessment grid (see Annex).

Simultaneously, we conducted six in-depth semi-structured interviews with stakeholders of the following organisations: ADA, FMEIA, OeAD, one Austrian participant institution and one participant institution of the partner countries. The aim of the interviews was to gain a deeper understanding of the structures, objectives, relevance and effectiveness of the programme. Moreover, the interviews served to discuss the respondents' expectations regarding the evaluation and the programme in terms of its impact hypotheses. The latter functioned as a basis for the reconstruction of the Theory of Change (see below).

Based upon the information gathered in the previous steps, Syspons reconstructed the Theory of Change of the APPEAR II Programme. By generating the Theory of Change we gained a clear understanding of the rationale for the programme being assessed. The Theory of Change served as a basis for discussion in a Theory of Change workshop which we conducted with ADA, FMEIA and OeAD. In this workshop, we presented the draft Theory of Change, on which basis a refined Theory of Change was constructed together with all stakeholders. This Theory of Change serves as the basis against which we will assess the programme's effectiveness as well as the suitability of its design and approach.

Based on the Theory of Change and the Terms of Reference, Syspons developed an evaluation assessment grid (see Annex). The information collected in the prior analysis was summarised and systemised in this analytical grid in the form of central evaluation questions and aspects relevant to the mid-term evaluation. We assigned indicators and/or descriptors to every aspect.

In the next step, we reviewed the existing secondary data in form of the evaluations as well as other relevant studies related to the programme. In particular, we examined the project-level evaluation that was conducted in 2018. The purpose was to identify what kind of data and operationalised concepts already existed in order to avoid the duplication of data collection or the usage of different concepts for evaluating the same unit of analysis. The evaluation assessment grid displays which data from the project-level evaluation will be used for this mid-term evaluation (programme level). Furthermore, we analysed project documents such as project/scholarship proposals and reports.

In parallel to the steps described above, we determined our methodological approach to evaluate the APPEAR II Programme. Our approach is specified in detail in the Inception Report.

Subsequently, Syspons delivered the draft of the inception report, which was discussed with ADA, FMEIA and OeAD in a workshop. All comments and feedback were documented and incorporated into the final version of the report. Afterwards, the final inception report was submitted and accepted by ADA.

\section{Collection and analysis phase}

This phase aimed at building a representative and comprehensive data base in order to answer the evaluation questions. For this, Syspons conducted semi-structured interviews with 36 key stakeholders of the APPEAR II programme. The interviews' main objective was to assess the relevance, programme design and approach as well as the effectiveness of the programme in more detail, by gaining in-depth insights from a broad range of perspectives. The list of interviewed persons can be found in the annex.

In order to carry out these interviews, we developed semi-structured interview guides based on the evaluation assessment grid. These interview guides included open qualitative questions and were tailormade for each stakeholder group, in order to respect their unique knowledge background concerning the APPEAR II programme. We conducted the interviews personally or via phone, depending on the availability and location of the interview partner. 
Parallel to the semi-structured interviews, Syspons implemented an online survey with all APPEAR II participant institutions. The objective of the survey was, first and foremost, to collect data on the programme's design and approach, its relevance and effectiveness. Using this online survey, we completed the data collected with the project-level evaluation that was implemented in 2018.

The online survey was carried out in English and we used the SurveyXact(C) software for its implementation. Before starting the actual survey, the questionnaire underwent two cognitive pre-tests, whose purpose was to review the comprehensibility of the questionnaire as a whole and also to review individual questions. Furthermore, the adequacy and completeness of the response categories was reviewed with the help of selected participants from the target group.

To start the online survey, each respondent received an email requesting his or her participation. This email included a personalised link to the online questionnaire. The online survey was conducted within three weeks. To guarantee a high response rate, we sent out an email reminder to the participants who had not yet replied after two weeks, and also two days before the deadline. Despite the personalised access to our survey system, we guarantee anonymous and confidential analyses of the collected data. The final response rate for the online survey was $71 \%$.

After the survey was completed, Syspons verified and validated the data. Subsequent to this quality assurance, we started with the assessment of the collected data from the online survey. From a methodological standpoint, the quantitative data analysis was divided into two steps. To begin with, we analysed the data using univariate statistical analysis such as frequencies, percentages or means. Furthermore, we used bivariate data analysis methods in order to find causal relationships between variables.

In addition, the evaluation team carried out a perception analysis in order to examine to what extent the perception of the programme's efficiency varies between, on the one hand, the responsible and implementing organisations and, on the other, the participant institutions. The data related to the perception of the participant institutions was collected using the online survey, while an additional mini online survey was carried out in order to collect the data from the responsible and implementing organisations. The final response rate for the mini online survey was $\mathbf{1 0 0 \%}$ since all eight invited persons from the responsible and implementing organisations participated in it.

As soon as the data analysis of the survey, the additional mini online survey and the implementation of the semi-structured interviews were completed, we started analysing the gathered data in order to ensure a transparent assessment and analysis of results. For this purpose, we aggregated the data using the evaluation assessment grid. The objective of this step was to reach overarching conclusions that are reflective of the evaluation results. All evaluation criteria were assessed based on quantitative and qualitative data as well as multiple data sources, which strengthens the validity of our results (triangulation of methods and data).

We reflected on the results of the previous analytical steps, compared insights and impressions and evaluated them jointly in an internal synthesis workshop. This workshop allowed us to incorporate the perspectives from all consultants in the evaluation results. Once again, this researcher triangulation increases the validity and reliability of the data analysis and, ultimately, the results of the evaluation. This triangulation also allowed us to analyse to what extent data collected through the interviews were either individual opinions or constituted a trend in the responses provided by the interviewees. In this vein, the evaluation team did not include individual opinions in the final analysis.

Afterwards, we conducted a validation focus group with members of ADA, FMEIA and OeAD in order to validate the evaluation's results. We structured the focus group discussion according to evaluation criteria.

Finally, we developed preliminary recommendations and options. We thereby aimed to create a strong and concrete basis for further development and discussion of the recommendations with ADA, FMEIA and OeAD. For this purpose, we first established tentative "fields of action" and identified potentials for optimisation within these fields. The preliminary recommendations and options will be later discussed and further developed in cooperation with ADA, FMEIA and OeAD in the last evaluation phase. 


\section{Reporting phase}

The objective of this phase was to document the conclusions and recommendations of the evaluation in a final report. For this, Syspons submitted a draft of the final report to FMEIA and OeAD at the end of August 2019. Moreover, we will present the findings of the report to ADA, FMEIA and OeAD in a workshop at the beginning of September. In this workshop, we will discuss the evaluation's results and develop the suggested options and preliminary recommendations into realistic and implementable recommendations. All feedback received in this workshop will be incorporated into the final report by Syspons, which will be submitted to ADA in mid-September.

\subsubsection{Methodological limitations of the mid-term evaluation}

The evaluation team has developed a tailor-made evaluation design that considered the specificities of the APPEAR II programme. Following current academic debates, the evaluation pursued the approach of Stern et al. (2012), according to which the most rigorous design is no longer equated with the experiment counterfactual approach, but rather with the quest to find the most appropriate design for a given context. This also means that it is possible to use more than one design - if feasible - to compensate for the weaknesses of other designs. Finally, it also means that we strive not only for a combination of designs, but also for a combination of methods. Therefore, in this mid-term evaluation, we will measure the effectiveness of the programme using a contribution analysis. Furthermore, we will combine different evaluation methods since we will carry out several individual and group interviews as well as an online survey for participant institutions and a mini online survey for the responsible and implementing organisations. We have also carried out a comprehensive desk research and analysis of secondary data and will have a validation focus group at the end of the data collection and analysis phase. Nevertheless, we have identified six challenges in the implementation of the evaluation approach:

- The online survey will not be used to collect data regarding the five basic principles and how the collaboration between the participant institutions functions. This data will be collected using only the interviews.

- The data collected by the evaluation at the project level (2018) will be used in this mid-term evaluation. In the framework of the project-level evaluation, an online survey was carried out, which was targeted at institutions that participated in the first and second programme phases. Since the present mid-term evaluation is limited to the second phase of the programme, it is necessary to filter out the data on the projects of the first programme phase. This data cleaning will be made using the data delivered by the participant institutions in the survey. ${ }^{3}$ Since the data is anonymized, it is not possible for us to guarantee that the projects are all correctly allocated to the right phase. Therefore, the data used from this previous project-level survey might include incorrect answers, rendering the results of this evaluation less valid.

- In order to limit the time and effort of the participant institutions while completing the online survey, the survey questions related to the achievement of the outcomes (effectiveness of the programme) and also included some questions on the programme design and approach (RACI analysis), which will not be operationalised in detail. This lack of operationalisation limits the comparability of the corresponding data collected with the online survey. It also means that the quantitative data will be collected only at a general level, while the qualitative data will be collected both at a general and detailed level.

- For the effectiveness analysis (see evaluation question 9 in the evaluation assessment grid), two different sources are being used to collect quantitative data. On the one hand, some data is collected using the online survey that was carried out within the project-level evaluation (2018). On the other hand, other data will be collected using the online survey carried out within

${ }^{3}$ The question that will be used to separate the projects of the first phase from the projects of the second phase is the following:

"What is the status of the APPEAR project you are associated with?". Respondents who answered the question with "completed"

belong to the first programme phase, while those who answered the questions with "ongoing" belong to the second phase. 
this mid-term evaluation. Depending on the source and the outcome that is being evaluated, the operationalization of the outcomes takes place at different levels: while the data regarding the achievement of some outcomes was collected using one single item (see project-level evaluation), the data for other outcomes is collected using various items that operationalize the whole spectrum of the intended outcome. The different operationalization levels will limit the quantitative comparison of the achievement of the programme outcomes.

- Furthermore, the scholarship holders (of both stand-alone scholarships and scholarships embedded in a partnership) are involved in the evaluation to a limited extent. While data regarding the scholarships embedded in partnerships will be collected using the online survey, the data from stand-alone scholarships cannot be collected using the same evaluation method. Therefore, five interviews with stand-alone scholarship holders will be carried out in order to directly reach these scholarship holders. However, since the number of interviews is limited, it is challenging to carry out rigorous analyses for the second programme component.

- The participant institutions are mainly involved in the evaluation through the online survey, in which they will evaluate themselves and the implemented projects. This (self-) evaluation can be biased since the same institutions that implement the projects also evaluate them. This potential bias could be tackled by implementing case studies, so that an evaluator could asses the projects from an external perspective. However, since no case studies are foreseen in this mid-term evaluation, the evaluation team must take this possible bias into consideration while carrying out the synthesis of the evaluation results. 


\section{Evaluation results}

This chapter presents the evaluation results and assesses them according to the evaluation criteria relevance, programme approach and design and effectiveness. The evaluation results stem from the analysis of documents and data (including previous evaluations), in-depth semi-structured interviews with 36 internal and external actors, an online survey of the participant institutions and a mini survey for the responsible and implementing organisations. ${ }^{4}$ The evaluation results were validated in a focus group with the responsible and implementing organisations.

The online survey for the participant institutions was open to 96 project members, from which 69 participated. This translates into a response rate of $\mathbf{7 1 \%}{ }^{\mathbf{5}}$. Furthermore, eight persons were invited to complete the mini online survey for the responsible and implementing organisations. All of them participated, which means a response rate of $\mathbf{1 0 0 \%}$.

\subsection{Relevance}

The criteria relevance refers to the raison-d'être of any given programme. Its analysis renders insights into whether a programme will be or is doing the right thing. Therefore, the question of whether a programme is relevant is the first question an organisation should answer even before a programme proposal is formulated or any actions are taken. When analysing the relevance of APPEAR II, it is necessary to first study whether the programme is in line with international strategies/frameworks and whether its concept is relevant in the context of current international debates on scientific cooperation in development. Moreover, the relevance of APPEAR II for the Austrian Development Cooperation Policy was also analysed by examining the consistency between the programme and the ADC strategies. Finally, the coherence of the APPEAR II programme within the ADA portfolio in the area of higher education/research was studied.

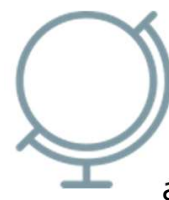

\section{Relevance of APPEAR II at the international level}

APPEAR II's design and approach need to be in line with international strategies/frameworks in the area of (scientific) development cooperation for the programme to be relevant at the international level. In this evaluation, it was analysed whether this alignment exists by identifying the relevant international strategies/frameworks and comparing them to the programme design. In this regard, the programme design was analysed, placing an emphasis on the programme's long-term goals, its structure, basic principles, added values and thematic focuses.

In this vein, the first element of the programme's design that was analysed was APPEAR II's longterm goals. In this regard, it is observed that the programme was conceived while the Millennial Development Goals (MDGs) were still in place. The MDGs were the result of an agreement between world leaders at the United Nations in order to fight poverty. This agreement took place in 2000 and was the road map for the international cooperation until 2015. While the MDGs were still in place, the main programme's long-term goal was to contribute to the poverty reduction in the partner countries. This long-term goal is line with the first MDG, namely Reduce Poverty and Social Exclusion.

However, the Sustainable Development Goals (SDGs) were agreed in the United Nations shortly after APPEAR II began. They came into effect in January 2016 and will guide the development cooperation until 2030 (Agenda 2030). The SDGs build on the MDGs and go beyond them since they include

\footnotetext{
${ }^{4}$ ADA, FMEIA and OeAD

5 This response rate includes only the respondents that answered the whole survey. In this response rate, six respondents that partially answered the survey were not included.
} 
new development areas and do not focus exclusively on developing countries. The SDGs foresee a holistic approach in order to develop the whole world (both Global South and Global North).

When examining the current goal setting of APPEAR II (using the reconstructed Theory of Change, see chapter 4.1), it is observed that APPEAR II's long-term goals are aligned with SDGs, since the main long-term goal of APPEAR II is to contribute to achieving the SDGs. For the programme to be able to make this contribution, it is foreseen that the participant institutions improve the scientific foundation in the partner countries and that the Austrian higher education institutions increase their commitment to development cooperation. It can be observed that the participant institutions (both in Austria and in the partner countries) play a central role in contributing to the achievement of the SDGs. This special role of the universities is corroborated by the scientific literature in the area of (scientific) development cooperation. For instance, F. El-Jardali, N. Ataya, \& R. Fadlallah $(2018$, p. 3$)$ indicate that "universities have opportunities and capacities to generate, translate and disseminate knowledge in order to contribute to the achievement of the SDGs".

The next element of the programme design studied in this evaluation is APPEAR II's structure. In order to carry out this analysis, the two programme components were examined individually:

- In the first component, partnerships between Austrian institutions and institutions of the partner countries are promoted. The desk research and interviews show that this component is aligned both with the SDGs and the MDGs, since partnerships for development are being fostered (SDG 17 and MDG 8). Furthermore, the first component is also in line with the Busan Partnership for Effective Development Cooperation. The Busan Partnership for Effective Development Cooperation was agreed in 2012 in order to improve the effectiveness of the development cooperation. For this, four principles were settled, namely i) ownership of development priorities by developing counties, ii) a focus on results, iii) partnerships for development, and iv) transparency and shared responsibility. In particular, APPEAR II is in line with the principle Partnerships for development, since the programme acknowledges that "development depends on the participation of all actors and recognizes the diversity and complementarity of their functions" (OECD, 2012).

- The second component of APPEAR II focuses on providing scholarships to Masters and PhD students from universities in partner countries. The interviews and desk research indicate that this component is also aligned with the international frameworks, especially with the SGDs, since the programme aims at improving the quality of education (SDG 4).

In a similar manner, the international relevance of APPEAR II's basic principles was studied and it was observed that the basic principles are in line with the international frameworks:

- The programmes' participatory approach is in line with the Busan Partnership for Effective Development Cooperation, since Partnerships for development are being promoted. In these partnerships, the projects are commonly designed and implemented, and therefore they reflect the diversity and complementarity of the functions of Austrian institutions and institutions from the partner countries. A participatory approach is also implemented in similar programmes conducted by other European organisations like the Flemish Interuniversity Council (VLIR), Académie de recherche et d'enseignement supérieur (ARES), German Academic Exchange Service (DAAD) and Nuffic.

- The culturally open-minded knowledge reflects the Paris Declaration on Aid Effectiveness. The desk research indicates that this declaration was approved in 2005 and aimed at improving the ownership, harmonisation, alignment, results and mutual accountability of development cooperation. APPEAR II is in line with the Paris Declaration since it bases its "overall support on partner countries' national development strategies, institutions and procedures" (OECD, 2005). Thus, APPEAR II respects different cultural, epistemological, methodological and empirical approaches during the generation of knowledge. In a similar manner, VLIR, ARES, DAAD and Nuffic also implement this approach in their programmes. 
- In addition, the interviews and the desk research show that the empirical-oriented approach is necessary for the programme to be able to achieve its long-term objectives. The programme will be able to contribute to achieving the SDGs (long-term objectives) only if the programme outputs and outcomes (for instance, research/teaching results) can be used in order to promote development in the partner countries (empirical-oriented approach). In the European context, different approaches are being implemented: while some organizations focus on supporting empirical-oriented research, others also support basic research (Grundlagenforschung). In this regard, there is not a correct or incorrect approach, but different orientations of programmes. For instance, Nuffic focuses on supporting empirical-oriented research, while organisations like VLIR and DAAD also fund basic research.

- Moreover, the desk research indicates that in terms of gender-sensitivity, APPEAR II is aligned with the SDGs and MDGs, since gender equality is promoted as a basic principle (SDG 5 and MDG 3). Similar programmes of VLIR, ARES, DAAD and Nuffic also apply a gender-sensitive approach. These programmes, however, do not focus on structural and procedural obstacles to women's advancement within the higher education sector.

- Finally, the bottom-up and demand-driven approach is in line with the Paris Declaration on Aid Effectiveness, since there is an alignment with the partners' needs and strategies when planning and implementing the APPEAR projects. Organisations like VLIR and ARES also implement programmes that apply this approach, while Nuffic and DAAD do not focus on it.

Continuing the relevance analysis of the programme design, the international relevance of the programme's added values ${ }^{6}$ was also examined. In this regard, it could be shown that these are aligned with the international frameworks and with international debates on scientific cooperation in development. While some added values represent state-of-the-art (which means that similar programmes are also implementing them), other added values make APPEAR II a pioneer programme. In particular, the alignment with the respective ADC country strategy and the consideration of the rights and needs of persons with disabilities differentiates APPEAR II from similar programmes.

- To begin with, the alignment of APPEAR II projects with the respective ADC country strategy assures that the portfolio of the ADC is politically coherent. In this regard, the interviews show that there is a trade-off between the political coherence and the programme's flexibility since, for instance, certain projects might not be funded due to their lack of alignment with the strategies. In comparison to similar programmes, APPEAR II took the decision to prioritize political coherence, while other programmes, such as the programmes of the DAAD, chose to keep their flexibility.

- $\quad$ Furthermore, the consideration of the rights and needs of persons with disabilities is not only in line with the United Nations Convention on the Rights of Persons with Disabilities but also with the SGDs. The United Nations Convention on the Rights of Persons with Disabilities was approved in 2006 and its objective "is to promote, protect and ensure the full and equal enjoyment of all human rights and fundamental freedoms by all persons with disabilities, and to promote respect for their inherent dignity" (UN, 2006). APPEAR II is in line with this international strategic document, since the programme aims at mainstreaming disability by including the needs and rights of persons with disabilities in the planning and implementation of the APPEAR II projects. As aforementioned, similar programmes of VLIR, ARES, DAAD or Nuffic do not focus on the rights and needs of persons with disabilities.

In addition, according to the Agenda 2030 (SDGs), "no one" should be left behind. When analysing this premise and comparing it to the programme design, the desk research and interviews show that this principle is being used since some "marginalized groups" should not be left behind in APPEAR II. The programme defines these marginalized groups as persons with disabilities

\footnotetext{
${ }^{6}$ APPEAR's added values that are not obligatory for a project to be selected, but if they are fulfilled, the project proposal will receive a better assessment.
} 
and women. Organisations like VLIR, ARES, DAAD or Nuffic are currently discussing which marginalized groups they should consider when implementing similar programmes.

- In addition, the regional networks are in line with both SDGs and MDGs, since partnerships for development are being fostered (SDG 17 and MDG 8). Similar programmes also foster regional networks and therefore this added value is state-of-the-art. The limitation regarding the $20 \%$ of the projects' budget available for participant institutions from third countries (see chapter 6.2 ) restricts the implementation of this added value according to the conducted interviews, since the participation of these additional institutions is (financially) limited. Nevertheless, with reference to the programme documents, the main focus of APPEAR II is to build partnerships and not networks. Therefore, like for all APPEAR II added values, regional networks are not a must but a nice to have. Similar programmes from VLIR, ARES, DAAD or Nuffic support to a greater extend the regional networks, in comparison to APPEAR II.

- Finally, the programme focuses on young scientists. As in other programmes, APPEAR II recognizes the need of young scientists for (more) training and research possibilities since they have not yet reached the pinnacle of their careers. In this regard, APPEAR II belongs to the state-of-the-art in comparison to similar programmes. In a similar manner, programmes of VLIR, ARES, DAAD and Nuffic also aim at reaching young scientists in a predominant manner.

The last element of the programme design examined in this relevance analysis is its thematical focuses. In this regard, it is observed that the programme's thematical focuses are internationally relevant since they are in line with the SDGs. The participant institutions can freely choose in which area they want to design and implement a project and can therefore choose to which SDGs they want to contribute with their projects. In this regard, APPEAR II is not thematically focused on certain SDGs but can potentially achieve any SDG.

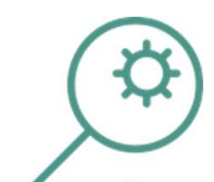

\section{Relevance of APPEAR II in Austria}

The evaluation examined the relevance of APPEAR II not only at the international level but also in Austria. This analysis was carried out from two different perspectives. To begin with, the relevance of the programme was examined in relation to the Austrian Development Cooperation Policy. Furthermore, the extent to which the programme is relevant for the Austrian institutions was also studied.

In order to analyse the relevance of APPEAR II in relation to the Austrian Development Cooperation Policy, four relevant strategic documents were identified and compared with the programme's design.

- To begin with, the desk research and interviews showed that the conception of APPEAR II was guided by the Three-year programme of the Austrian development cooperation 20162018. This three-year programme includes seven principles ${ }^{7}$ of the ADC. In particular, two of those principles indicate that i) "development cooperation is help towards self-help" and ii) "partnership can only come about if we treat each other as equals and plan and carry out projects together" (FMEIA, 2017a). APPEAR II is in line with these principles since the partner institutions plan and carry out their projects in an independent manner (self-determination), and since APPEAR partnerships should be between equals (ownership).

Furthermore, this three-year programme presents five goals and priorities ${ }^{8}$ that should be achieved with the ADC. APPEAR II contributes to three of these goals, namely poverty reduction,

\footnotetext{
${ }^{7}$ The seven pinciples are: i) Self-determination - All human rights for all; ii) Ownership - Partnership of equals; iii) Bringing development cooperation into the mainstream of society; iv) Policy coherence for development - All actors working together; v) Sustainable development; vi) Management for results; and vii) Internationality.

8 The five goals and priorities are: i) Contribution to poverty reduction, ensuring peace and human security, promoting sustainable economic development and preserving the environment in keeping with the development-policy objectives set out in the Federal Development Cooperation Act; ii) Promotion of human rights, freedom and self-determination for all people in disadvantaged regions of the world; iii) Conformity with the Sustainable Development Goals and the aims of our partner countries; iv) Use of
} 
the achievement of the SDGs, and the use of specific Austrian know-how, capacities and experience.

In addition, this strategic document defines four thematic priorities ${ }^{9}$ and two cross-cutting issues $^{10}$ for the ADC. APPEAR II is also in line with this document, since it is active in one of the thematic priorities, namely education, and deals with one of the cross-cutting issues, namely gender.

- The aforementioned three-year programme was subsequently replaced by the Three-year programme of the Austrian development cooperation 2019-2021. This document indicates that the ADC should focus on achieving the SGD. In this regard, APPEAR II is in line with this strategic document since the programme's main long-term goal in to contribute to the achievement of the SDGs.

- Furthermore, the ADC strategy related to Higher Education and Scientific Cooperation was also identified in the desk research as a relevant strategic document. According to this document, the ADC should be active in the following five key areas: i) institutional capacity development; ii) quality assurance and quality enhancement; iii) cooperation and partnerships; iv) development research; and v) focus on certain regions. APPEAR II is in line with this strategic document since it is working in all of these key areas.

- Finally, the Manual Capacity Development should also influence APPEAR II's design and implementation. APPEAR II reflects this strategic document since its design uses the programmatic approaches and methods presented in this manual, and since APPEAR II's approaches and methods are adapted to the realities of the partner institutions and the partner countries.

The alignment of APPEAR II with the Austrian Development Cooperation Policy was confirmed through the secondary data (see Figure 3 ) and the interviews. In particular, the interviews with the ADC coordination offices showed that the local offices would like to connect different ADC programmes but cannot do so due to a lack of resources. For instance, an APPEAR project on animal feed generated research results that an ADC local office wanted to include in its bilateral programme. However, this matching was not possible due a lack of resources in the local office.

Figure 3: Relevance regarding Austrian development policy

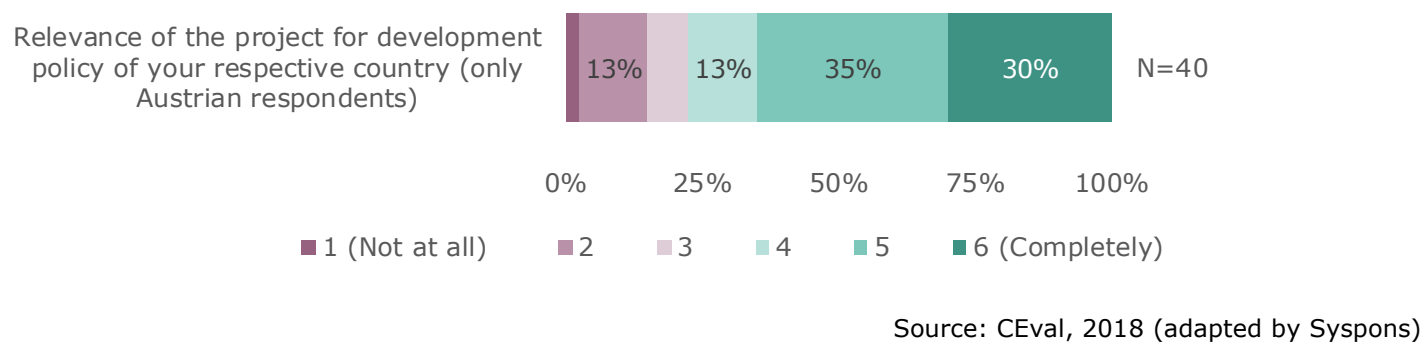

Regarding the relevance of APPEAR II for the Austrian institutions, the secondary data shows that the programme covers their needs (see Figure 4). The interviews showed that the Austrian institutions profit from APPEAR II in order to tackle global challenges that they cannot solve alone, such as climate change.

\footnotetext{
specific Austrian know-how, capacities and experience; and v) Protection of global public goods, such as health, environment and the climate system.

9 The four thematic priorities are: i) education; ii) ensuring peace and human security, human rights and migration; iii) water energy - food security; and iv) private sector \& development.

10 The two cross cutting issues are: i) environmental and climate protection; and ii) gender equality.
} 

university (only Austrian respondents)

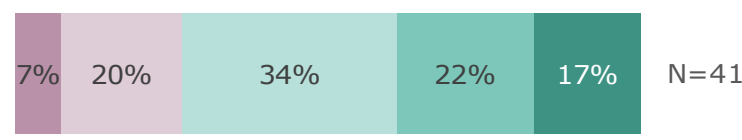

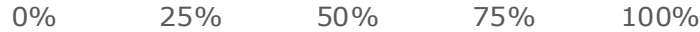

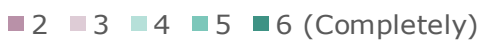

Source: CEval, 2018 (adapted by Syspons)

However, the interviews also indicated that in comparison to the partner institutions, the Austrian institutions have stronger pressure to publish excellent scientific research. Since the APPEAR II programme does not focus on excellent research but rather on developmentally relevant research (see chapter 6.2), the needs of the Austrian institutions are not completely covered by the programme. Moreover, the interviews showed that the Austrian institutions consider that the SDGs should be achieved principally in the partner countries. Thus, there is no clear reflection and understanding that the SDGs should be also achieved in Austria or which role the Austrian institutions should play in this context.

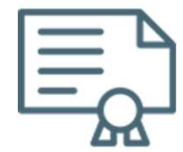

\section{Coherence between APPEAR II and the ADA portfolio in the area of higher educa- tion/research} with other initiatives contained in the ADA portfolio in the area of higher education/research. To begin with, the following initiatives in the respective portfolio were identified using the interviews:

Figure 5: ADA portfolio in the area of higher education/research

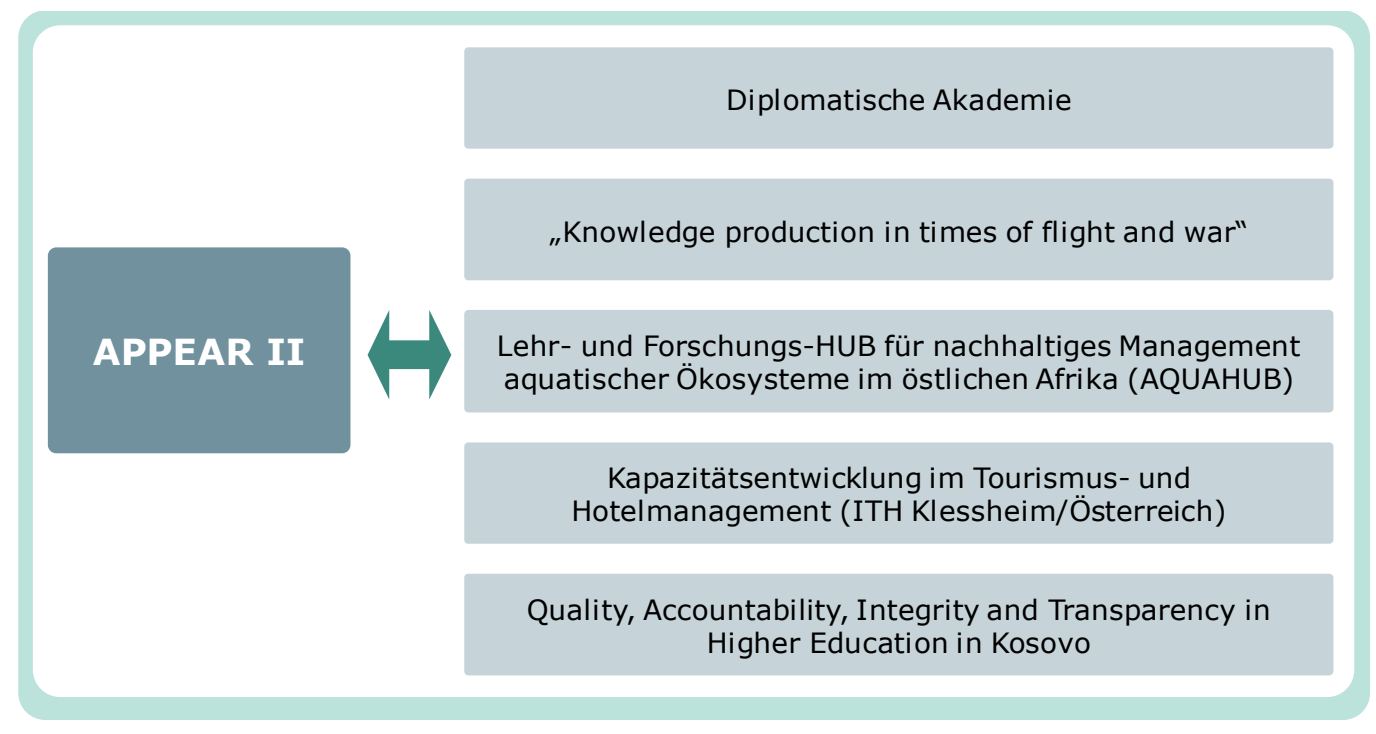

Source: Syspons, 2019

After examining the different initiatives, its goals, target groups, thematical and regional focuses, it was observed that there is no significant overlap between the initiatives. APPEAR II is the central programme of the portfolio since it covers the largest and most different thematical focuses, and because its budget considerably exceeds the budgets of the other initiatives. Even if the other initiatives work on similar topics and possibly in the same regions, they complement APPEAR II in a precise manner. 


\subsubsection{Relevance assessment}

The evaluation team concludes that APPEAR II is highly relevant at the international level, since it is in line with international strategies/frameworks regarding its long-term goals, structure, basic principles, added values and thematical focuses. In this regard, the programme design is aligned with the SDGs, MDGs, the Paris Declaration on Aid Effectiveness, the Busan Partnership for Effective Development Cooperation and the United Nations Convention on the Rights of Persons with Disabilities.

Regarding the programme's added values, the evaluation team concludes that APPEAR II is a pioneer when it comes to the alignment of its projects with the respective ADC country strategies and consideration of the rights and needs of persons with disabilities. These two added values are not being implemented by similar programmes, and therefore make APPEAR II a unique programme in the area of cooperation in the tertiary education sector. Nevertheless, the evaluation team concludes that there is potential for expanding the concept of "marginalized groups" ("leave no one behind" in the Agenda 2030), since it is currently being limited to persons with disabilities and women.

In addition, the evaluation team concludes that APPEAR II is highly relevant at the Austrian level, since it is in accordance with the Austrian Development Cooperation Policy. In this regard, the evaluation team concludes that the programme is in line with the Three-year programmes of the Austrian development cooperation 2016-2018 and 2019-2021, with the Strategy of Higher Education and Scientific Cooperation, and with the Manual Capacity Development. Nevertheless, there is potential for improvement regarding the harmonisation of different ADC programmes by the ADC local offices (for example, the results of APPEAR projects could be connected with the different bilateral programmes in the partner countries). Furthermore, the evaluation team concludes that the programme does not focus on achieving the SGDs in Austria. In this vein, it is unclear which role the Austrian higher education institutions should play in order to contribute to the achievement of the SDGs in Austria.

Finally, the evaluation team considers that the initiatives of the ADA portfolio in the area of higher education/research (including the APPEAR II programme) are coherent and complementary. Thus, there is no significant overlap between APPEAR II and the initiatives. On the contrary, the other initiatives complement APPEAR II in a precise manner.

\subsection{Programme design and approach}

APPEAR II's design and approach have a strong bearing on the overall quality of the programme. Therefore, the evaluation analyses to what extent the programme's conception allows or hinders smooth programme implementation and how the OeAD is implementing the second programme phase. Furthermore, it also examines how the programme design influences the achievement of programme goals. Thus, this chapter discusses to what extent APPEAR II's design and approach ensure an efficient and effective implementation.

\section{Efficiency analysis of the programme's design and approach}

In order to answer this question, the efficiency of the programme was analysed at two different levels. On the first level, the design and approach of the two components and its influence on the programme efficiency was studied. On the second level, the general implementation of the programme by the OeAD was examined, placing special focus on the programme's public relations.

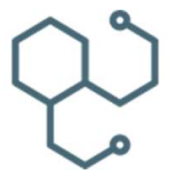

\section{Design and implementation of the first programme component}

In the first component, partnerships between higher education and/or research institutions in Austria and the partner countries are fostered. The establishment and consolidation of these partnerships takes place using three instruments, namely the Preparatory Funding, Academic Partnerships and Advanced Academic Partnerships. Three central parameters influence the way these 
instruments are planned and implemented: the duration of the projects, project budgets and the selection of the partner countries.

In general, the participant institutions consider that the three parameters allow them to develop adequate proposals. In this regard, the online survey indicates a general acceptance of the parameters (see Figure 6) and this tendency is confirmed by the interviews. Furthermore, the interviews show that the projects' implementation requires a duration of up to four years. Since some of the participant institutions are working together for the first time, it is likely that the first year is spent setting up the foundations of the project and/or cooperation between the participant institutions.

Figure 6: Parameters of the first programme component

I think that the maximum duration of the APPEAR projects is adequate.

I think that the project budgets are adequate.

I think it is adequate that a maximum of $20 \%$ of the project budget can be allocated to partner institutions located in countries different to the eligible countries.

I think it is adequate that the APPEAR programme focuses on 16 partner countries that are partner countries of the Austrian development cooperation.
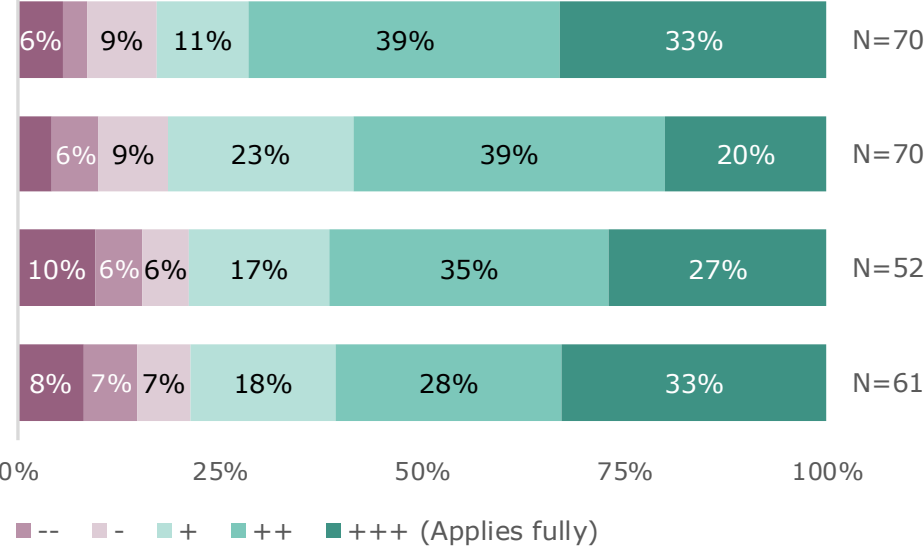

Source: Syspons, 2019

Additionally, the interviews point out the central role of the Preparatory Funding in identifying the partnerships that are likely to be successful. If cooperation between the participant institutions does not function well during the execution of the Preparatory Funding, it is unlikely that they will generate a further application for an Academic Partnership.

Once the applications are selected and the projects begin, the OeAD supports the participant institutions in an adequate manner and the implementation of the first component works smoothly. This was shown by the online survey (see Figure 7) and confirmed in the interviews. The exception to this, according to the interviews, is the financial processing of the projects. Due to an external control implemented by the Federal Audit Office (Bundesrechnungshof) on the ADA, the requirements for the financial processing of the projects were increased. Therefore, the projects had to deliver additional evidence of financial execution (e.g. additional invoices) and the OeAD had to revise the financial information of the projects repeatedly during their implementation. 
Figure 7: Implementation of the first programme component

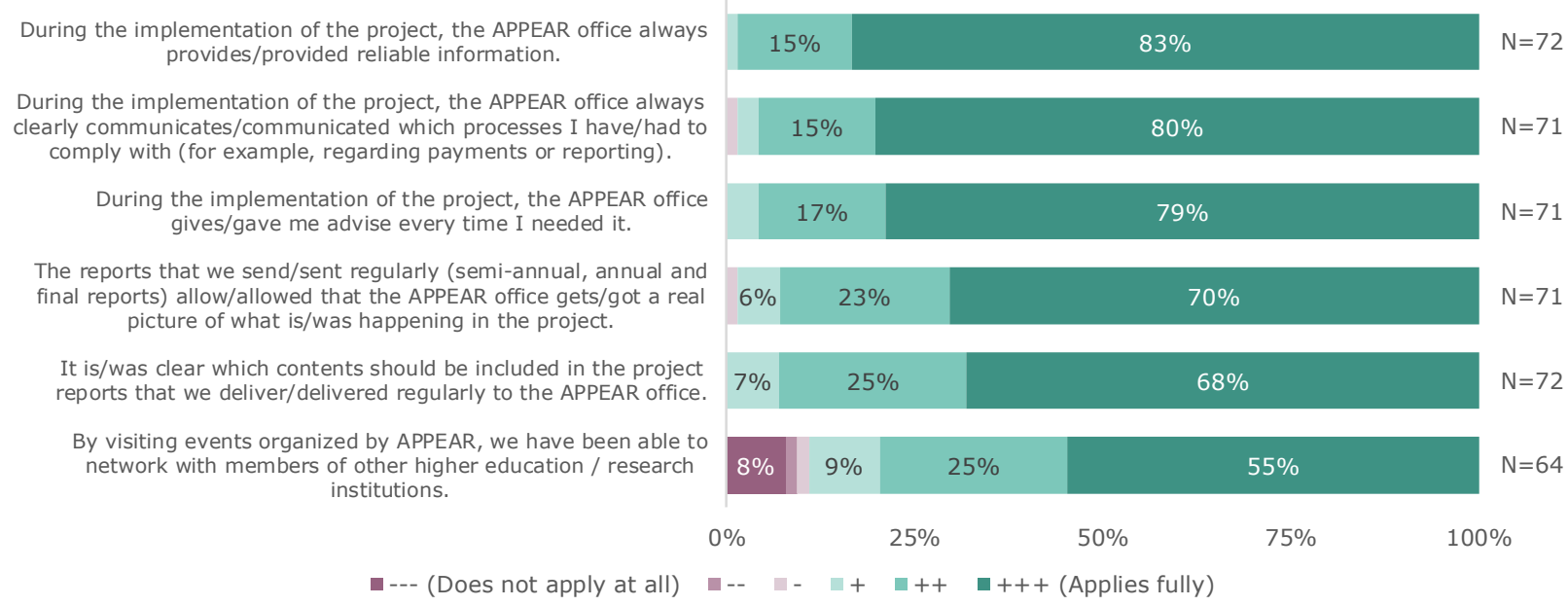

Source: Syspons, 2019

In addition, the OeAD is monitoring the different projects that are being implemented using various types of narrative and financial reports that the participant institutions had to complete. Nevertheless, the desk research shows that the programme monitoring is taking place at activity level, and therefore the reporting data delivered to the ADA does not include a regular assessment of the achievement of the component goals.

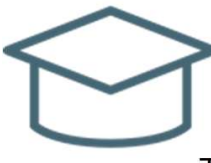

Implementation of the second component and its interlinkage with the first component

The second component is intended to provide scholarships to Masters and PhD students from universities in partner countries. Some of these scholarships are embedded in partnerships of the first component and some are stand-alone-scholarships. In order to analyse the efficiency of this component, the evaluation team examined how the OeAD implements both types of scholarships.

The online survey shows that the OeAD supports scholarship holders in an adequate manner (see Figure 8). This data was confirmed in the interviews, where it was also mentioned that the scholarship holders extensively profit from the know-how of the OeAD and can therefore focus on their studies, instead of dealing with administrative matters.

Figure 8: Implementation of the second component

During the APPEAR scholarship, the APPEAR office gives/gave the scholarship holder(s) advise every time he/she/they need/needed it.

During the APPEAR scholarship, the APPEAR office always clearly communicate/communicated the scholarship holder(s) which processes he/she/they must comply with. During the APPEAR scholarship(s), the APPEAR office always provides/provided reliable information to the scholarship holder(s)

It is/was clear which contents should be included in the reports that the scholarship holder(s) deliver yearly to the APPEAR office.

The yearly reports that the scholarship holder(s) send(s) regularly allow that the APPEAR office gets a real picture of what is happening in the scholarship(s).

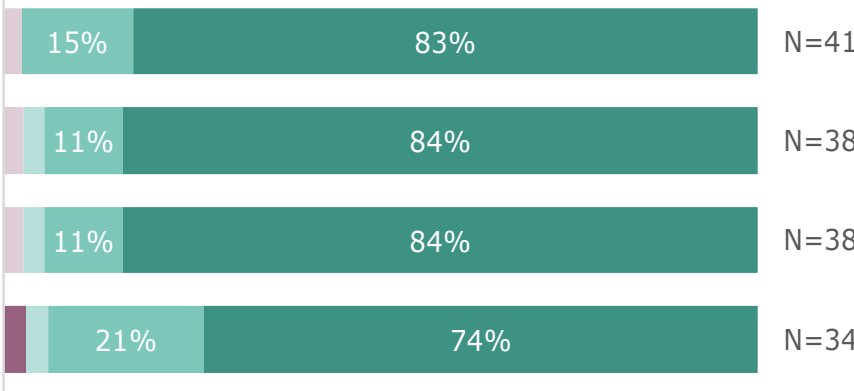

$63 \% \quad N=32$

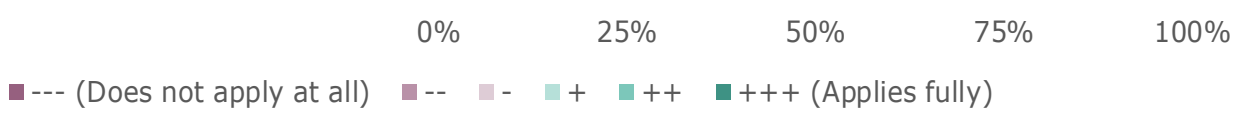

Source: Syspons, 2019 
As in the first component, the OeAD monitors the APPEAR scholarships at the activity level. Therefore, the information provided by the OeAD to the ADA in their annual reports contain descriptions of the development of different scholarship holders but does not include an assessment of the achievement of the component goals.

Furthermore, the evaluation studied to what extent the second component supports or has linkages with the first component. It was observed that there is an evident link between the first component and the embedded scholarships. However, the link is not evident when analysing the standalone scholarships. While the embedded scholarships focus on improving the organisational capacity development of the participant institutions, the stand-alone scholarships focus on improving the individual capacities of the scholarship holders.

Furthermore, the interviews show that both types of scholarship holders (embedded and stand-alone) deal with uncertainties when leaving their countries in order to carry out their studies in Austria. The interviews showed that only some of the scholarship holders can apply for study leave, while others must quit their jobs and it is therefore uncertain whether they will return to their institutions.

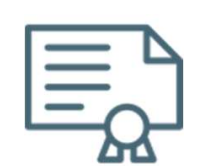

\section{Public relations of APPEAR II}

The objective of the programme's public relations is to publicise the programme within and beyond the participant institutions. For this, the programme has five different communication channels which are the APPEAR's website, events, radio transmissions, newsletter and publications.

All channels are being used by the participant institutions, as the online survey results show (see Figure 9).

Figure 9: Use of public relations channels by participant institutions

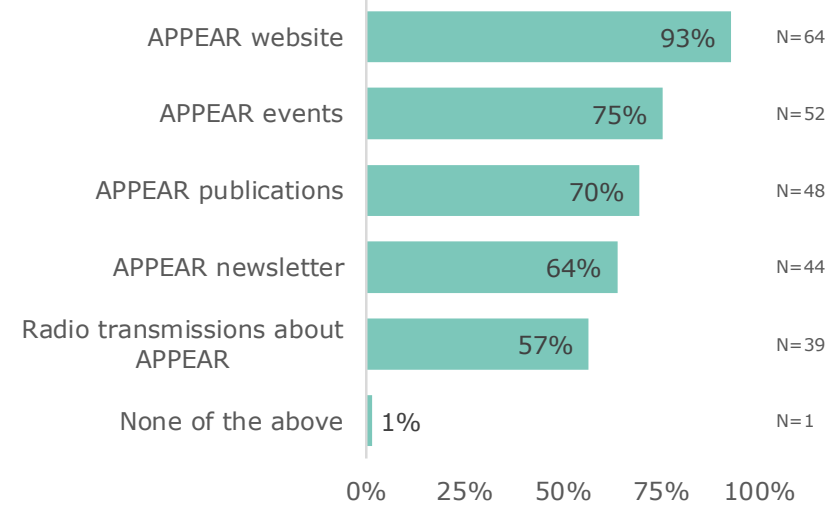

Source: Syspons, 2019

In addition, the online survey shows that these channels are not only being used, but are widely accepted by the participant institutions (see Figure 10). However, the interviews indicate that the participant institutions with very little or no international experience need to be connected to other institutions in partner countries or in Austria in order to be able to design and implement projects. The OeAD provides this facilitation between institutions. However, this facilitation is not being used in a systematic manner by the academic/research institutions, since many of them are not aware of this service. 


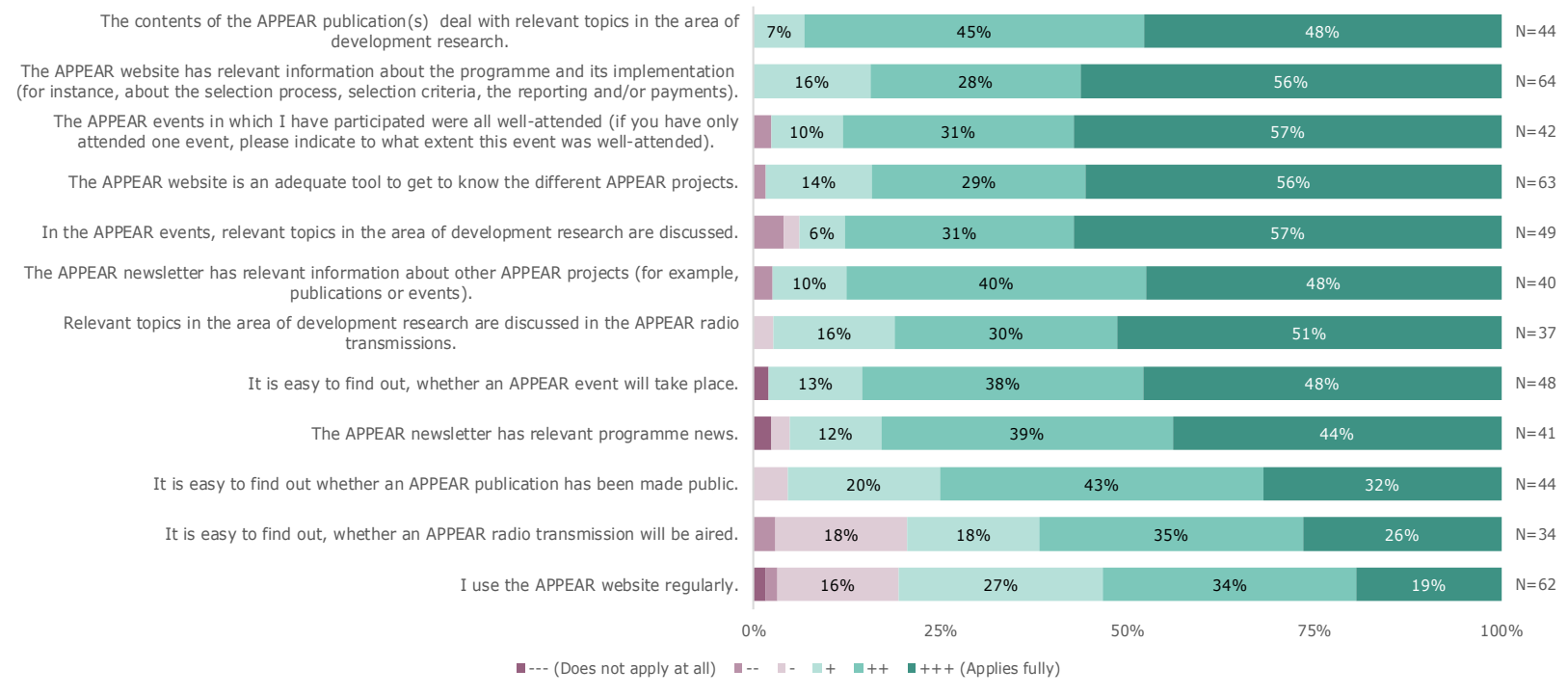

Source: Syspons, 2019

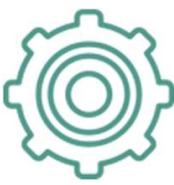

\section{The role of the OeAD in the programme implementation}

The OeAD not only implements the first and second component but has also implemented the first and second phase of the programme. In general, the participant institutions consider that the role of the OeAD contributes positively to their projects. This was revealed by the online survey (see Figure 11) and confirmed in the interviews.

Figure 11: Programme implementation by the OeAD

The support that we receive/d from the APPEAR office contributes positively to the achievement of the project results.

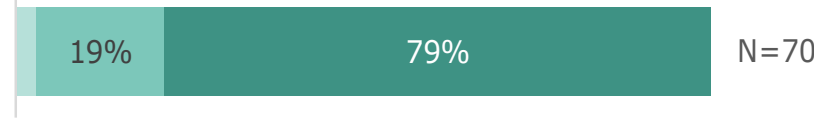

$$
\begin{aligned}
& \begin{array}{llll}
0 \% & 25 \% & 50 \% & 75 \%
\end{array} \\
& \text { घ--- (Does not apply at all) } \quad--\square-\square+\square++\quad \square+++ \text { (Applies fully) }
\end{aligned}
$$

Source: Syspons, 2019

The interviews also showed that the OeAD possesses a high expertise both content-wise (regarding development cooperation in the tertiary education sector) and regarding the implementation of the programme. For example, when implementing the second component, the OeAD possesses an extensive portfolio from which the scholarship holders can profit. This portfolio includes various services such as consultation support for obtaining visas.

In addition, the interviews indicate that the OeAD implements the programme in a flexible manner and considers unexpected situations that arise in the partner countries. According to the interviews, the participant institutions value and appreciate this flexibility, since it affects positively the projects' implementation and their achievements.

Furthermore, the general implementation of the programme by the OeAD was evaluated using a perception analysis, which integrate scales based upon semantic differentials. The objective was to juxtapose the perceptions of internal ${ }^{11}$ and external ${ }^{12}$ stakeholders, and use this comparison to draw analytical insights into the programme's efficiency. According to the collected data, both internal and external actors assessed the programme implementation in a positive manner. In addition, the

\footnotetext{
${ }^{11}$ ADA, FMEIA and OeAD

12 Participant institutions.
} 
collected data shows that there is a correspondence between the internal and external perceptions, as shown in the following figure.

Figure 12: Perception analysis

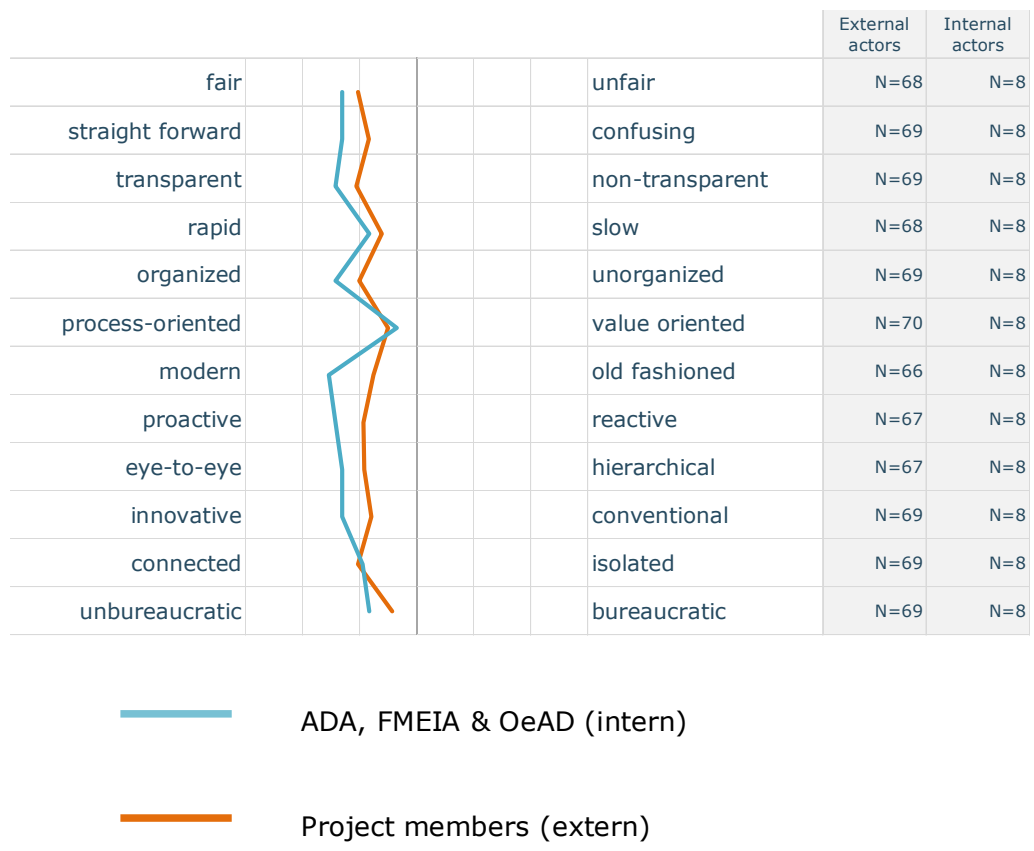

\section{Analysis of the effectiveness of the programme's design and approach}

In order to carry out this analysis, the plausibility of the impact pathway was examined and in particular, how the programme design and approach influence whether the programme objectives can be achieved in the long run.

The analysis of the impact pathway shows that all assumptions of the Theory of Change are logical and plausible (see chapter 4.1). At the same time, this analysis shows that the long-term objectives of the programme can be achieved only when the programme's outputs and outcomes are developmentally relevant for the partner countries and their institutions. Otherwise, it would not be possible for APPEAR II to contribute to achieving the SDGs (long-term impact). In order to ensure that the programme's outputs and outcomes are developmentally relevant, the programme design has three different mechanisms:

1. APPEAR II offers the Preparatory Funding which allows eye-to-eye planning of the projects. This ensures that the needs of the partner countries and its institutions are considered while planning the respective APPEAR II projects.

2. Further, when filling out the application forms for the Academic Partnerships and Advance Academic Partnerships the applicants must state to what extent their projects contribute to the following three topics:

- "Contribution to the partner countries' national / regional development strategies"

- "Beneficiaries (needs and demands) and relevance for local societies"

- "Capacity development of the partner institution(s) in the addressed country(ies)"

In this way, the institutions are required to reflect whether the needs of the partner countries and their institutions are covered by their projects.

3. In addition, the relevance assessment of the ADC local offices is considered during the selection process in order to decide whether a project should be supported or not. When the ADC local 
offices consider that the project's results are not developmentally relevant, it is less likely that the application is selected.

These three mechanisms ensure that the programme focuses on projects that have an empirical relevance (instead of a theoretical relevance). This was corroborated in the interviews, where several interviewees confirmed that the APPEAR projects are highly relevant both for the partner countries and their institutions.

\subsubsection{Programme design and approach assessment}

The evaluation team concludes that the programme design and approach enable an efficient implementation of APPEAR II. In this regard, the evaluation team considers that the first and second component are being smoothly and efficiently implemented. In this vein, both participant institutions and scholarship holders are highly satisfied with the programme's implementation. In particular, concerning the implementation of the first component, the evaluation team concludes that a duration up to four years is ideal in order to carry out the Academic Partnerships in an efficient manner. This is due to the fact that at the beginning of the projects, the participant institutions need time to get to know each other and establish foundations for cooperation.

Furthermore, it is observed that the first component is supported by the embedded scholarships, but not by the stand-alone scholarships. This, since the embedded scholarships focus on improving the organisational capacities of the participant institutions while the stand-alone scholarships focus on improving the individual capacities of the scholarship holders. However, separating the stand-alone scholarships from the APPEAR programme is not efficient, since it would mean more administrative costs for ADA (for instance, instead of carrying out one tender process, it would be necessary to implement two tender processes). Therefore and in order to improve the programme's coherence, there is potential for better integrating the stand-alone scholarships in APPEAR's rationale.

In addition, the evaluation team considers that there is potential for improvement regarding the programme's monitoring system (first and second component), since the actual system focusses on monitoring the programme activities. However, the state-of-the-art regarding monitoring systems indicates that the programme should focus on monitoring its effects/results.

When analysing the general implementation of APPEAR II by the OeAD, the evaluation team concludes that the OeAD is highly efficient since it deploys its specific know-how (both in the area of development cooperation in the tertiary education sector and regarding the implementation of APPEAR II). In addition, the OeAD is also implementing the programme's public relations in an efficient manner, since the public relation's channels are being widely used and accepted by the participant institutions. However, there is potential for improvement in this regard since universities with little or no international experience need to be connected to other universities with which they can develop and implement APPEAR projects. The OEAD is offering this facilitation, but the service is not being used by the academic/research institutions in a systematic manner since many of them are not aware of it. Thus, the facilitation by the implementing organization could be better advertised.

Furthermore, APPEAR II's design and approach allow an effective programme implementation. In this vein, the impact pathway of APPEAR II is plausible since the programme's design ensures that the programme outputs and outcomes (teaching, research, etc.) are developmentally relevant both for the partner countries and their institutions. In this way, the long-term achievements of the programme (contribution to the achievement of the SDGs) is plausible. For this purpose, APPEAR II assures this relevance using three mechanisms anchored in its programme design: i) Preparatory Funding; ii) the application forms for the Academic Partnerships and Advanced Partnerships; and iii) the relevance assessment of the ADC local offices in the selection process. 


\subsection{Effectiveness}

The rationale behind APPEAR II is to strengthen capacity in the scientific and higher education sector and to gain deeper insights into challenges and potential solutions to development obstacles. The programme thereby aims at enhancing the wider national development of the partner countries. In order to establish how far APPEAR II has achieved its (intermediate) objectives, the overall rationale of enhancing the scientific and higher education sector must be broken down into its more specific four objectives. These four objectives are also identified in the reconstructed Theory of Change (see chapter 4.1) and they are: i) improving teaching quality; ii) improving research quality; iii) improving organisational capacities; and iv) generating dialogue and cooperation.

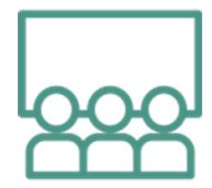

\section{Improving teaching quality at the participant institutions}

Improving teaching quality at the participant institutions is a crucial objective of APPEAR II, as teaching disseminates knowledge and skills and thereby acts as a multiplier mechanism for enhancing capacities. In this regard, the majority of participant institutions consider that APPEAR II improved their teaching quality according to the secondary data (see Figure 13 and Figure 14). Furthermore, the interviews show that APPEAR II allows participant institutions to learn from each other in the field of curriculum development, for instance when jointly developing a Master's programme. In particular, the interviews demonstrate that partner institutions benefit from exposure to good practices in didactics and other teaching methods used by the Austrian institutions.

Figure 13: Teaching quality at partner institutions

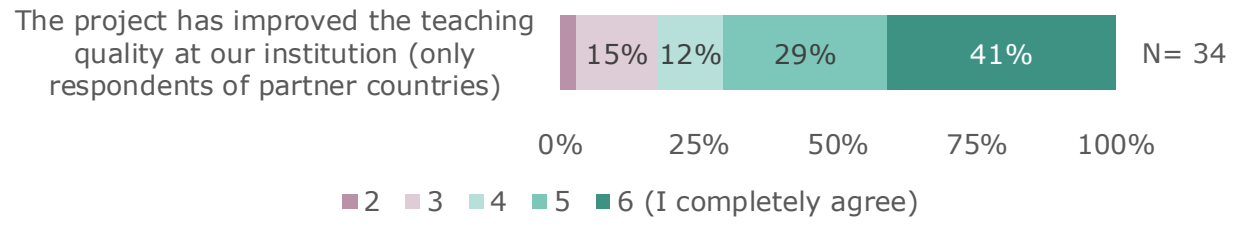

Source: CEval, 2018 (adapted by Syspons)

Figure 14: Teaching quality at Austrian institutions

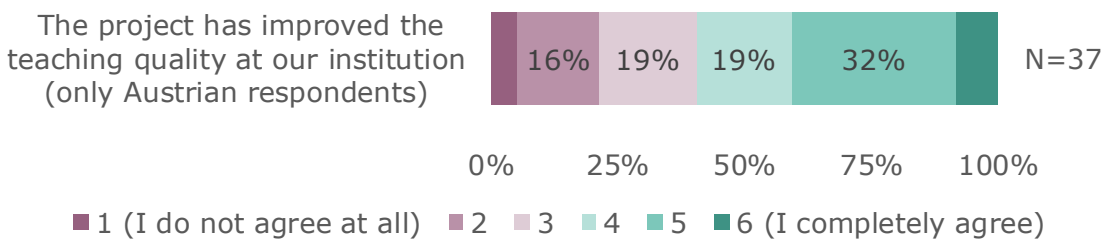

Source: CEval, 2018 (adapted by Syspons)

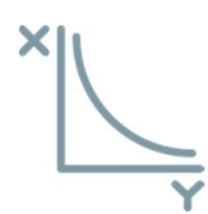

Improving research quality at the participant institutions

The quality of research conducted by the participant institutions is crucial since only highquality research can identify development obstacles and find solutions to them. Gaining deeper insights into potential solutions to development obstacles is, in turn, the rationale behind APPEAR II's support for the scientific and higher education sector.

Data collected on APPEAR II's effects on research quality of the participant institutions present a similar picture to that on teaching quality. Participant institutions consider that the quality of their research had improved through APPEAR II (see Figure 15 and Figure 16). Moreover, the interviews show 
that the participant institutions valued the exchanges on respective research perspectives, having access to a wider research network, improved research equipment and facilities, as well as better access to empirical data through, for instance, conducting field research in the partner country.

Figure 15: Research quality at institutions in partner countries

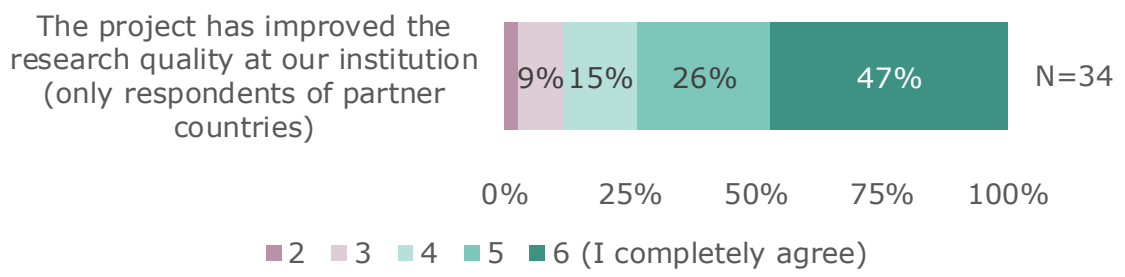

Source: CEval, 2018 (adapted by Syspons)

Figure 16: Research quality at Austrian institutions

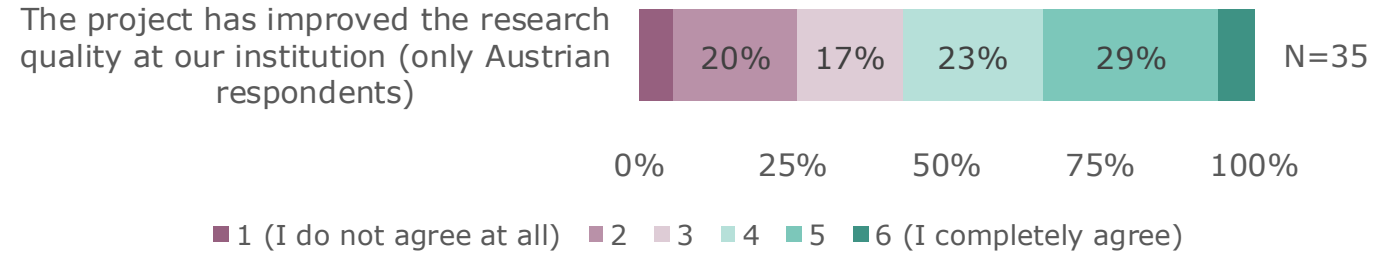

Source: CEval, 2018 (adapted by Syspons)

Moreover, the evaluation examined to what extent APPEAR II has contributed to improving the visibility of development research issues among the Austrian academic/scientific public. In this regard, the online survey shows that both interest in carrying out development research and the number of scientific papers at Austrian institutions have increased as a result of APPEAR II (see Figure 17). However, the interviews indicate that the visibility of development research issues has principally increased among the participant institutions and not among the wider Austrian academic/scientific public. Interviewees reported that the OeAD is not present in all relevant networks of the wider academic/scientific public, where APPEAR II's development issues could be raised.

Figure 17: Visibility of development research issues among the Austrian academic/scientific public

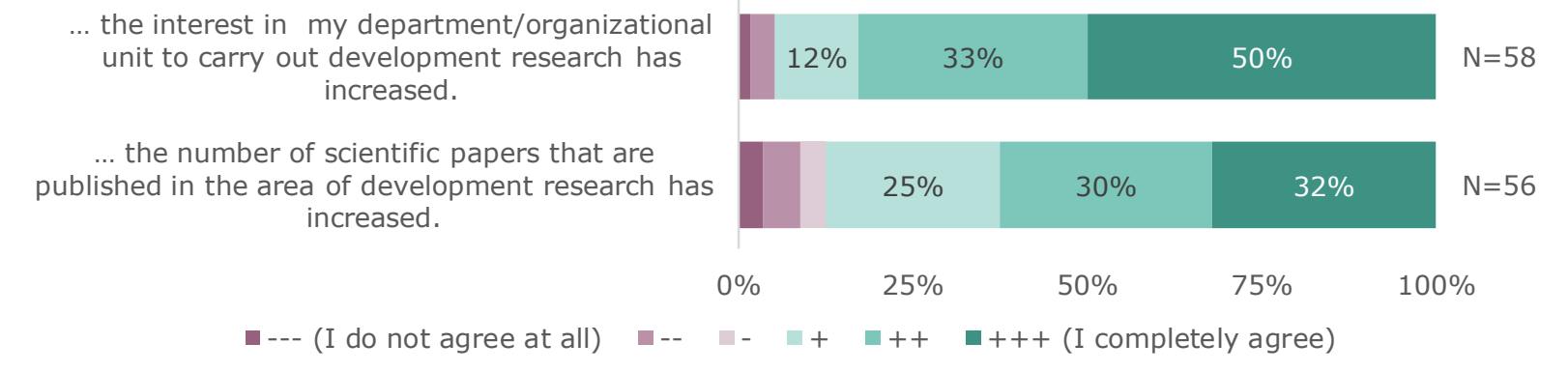

Source: Syspons, 2019 


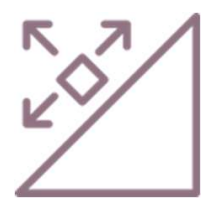

\section{Improving organisational capacities}

By improving the organisational capacities of participant institutions, APPEAR II aims at ensuring sustainable capacity building. In this regard, the evaluation examined to what extent these capacities are being improved in terms of the participant institutions' structures, processes and human capacities.

According to the online survey data on human capacities, APPEAR II had improved in particular the project management skills of project coordinators (see Figure 18). The interviews showed that project staff's management skills are enhanced through the discussion of project management questions with the other institution in the partnership. To a lesser extent, the online survey shows that participant institutions consider that their processes and structures have been improved through their participation in the programme. However, none of the six interviewed partner institutions where able to provide an example of changes in their processes and structures due to APPEAR II. This indicates that although the programme is achieving results in this area, the programme focuses on improving the management skills of project coordinators and not on improving the processes and structures of the participant institutions.

Figure 18: APPEAR II's effects on the organisational capacities of participant institutions

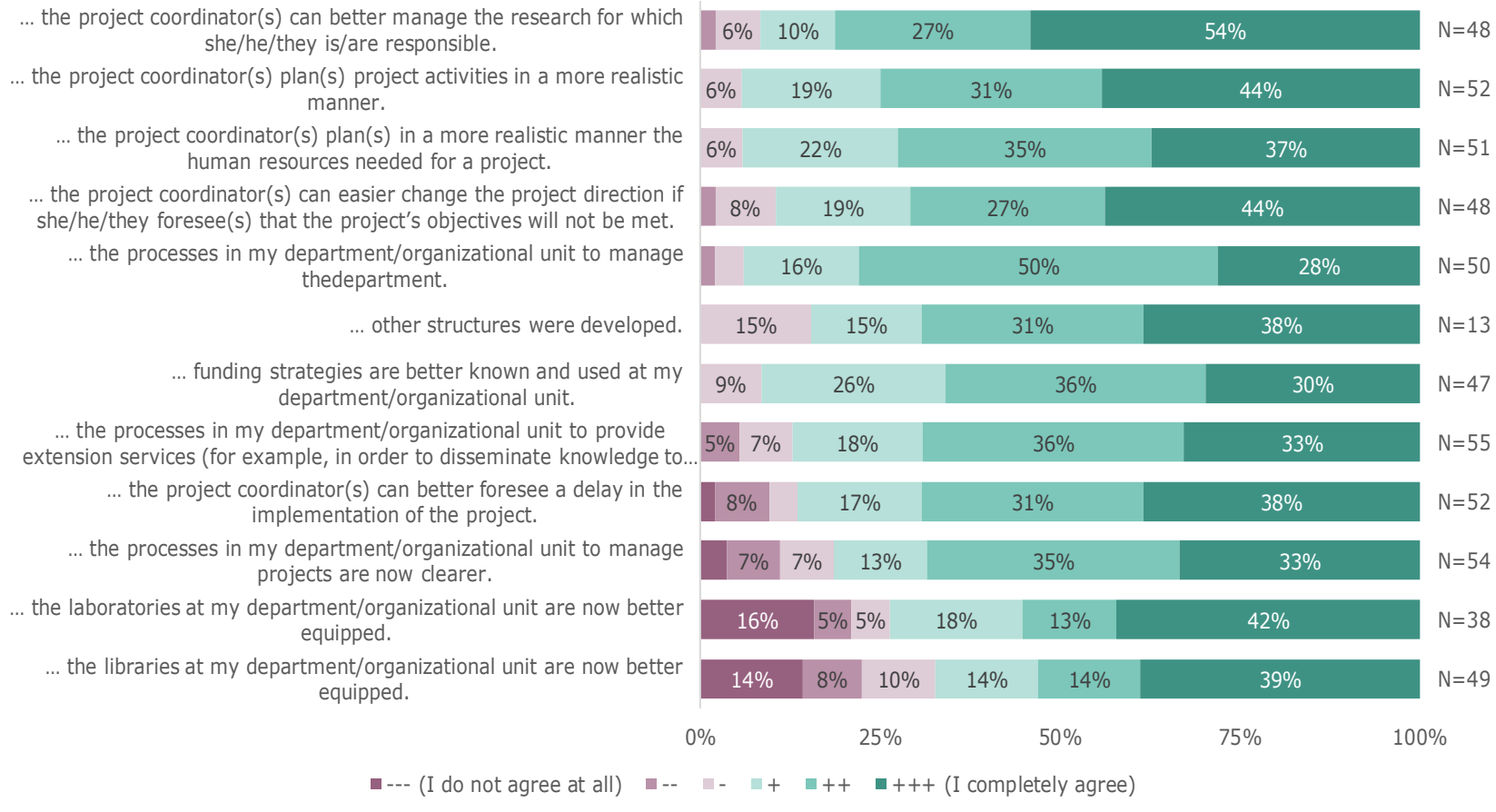

Source: Syspons, 2019

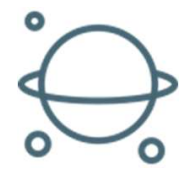

\section{Generating dialogue and cooperation between participant institutions}

APPEAR II aims at generating dialogue and cooperation between participant institutions by allowing for the exchange of knowledge and ideas between participant institutions. According to the secondary data, participant institutions consider that APPEAR II has improved dialogue and cooperation among them (see Figure 19). Moreover, the interviews show that APPEAR II's Preparatory Funding allows the programme to focus on those partnerships which are likely to work well in the future. This is because during the preparatory funding phase, the participant institutions can test their working relationship. Therefore, the Preparatory Funding contributes to achieving higher results in terms of dialogue and cooperation between participant institutions. This is confirmed in the interviews, when participant institutions stated that the Preparatory Funding helped them hold joint discussions on 


\section{SYS \\ $P O N S$}

the topic for their future project. Moreover, the interviewees stated that the Preparatory Funding also helped them find the right project partner in the first place.

Figure 19: APPEAR II's effects on dialogue and cooperation between the participant institutions

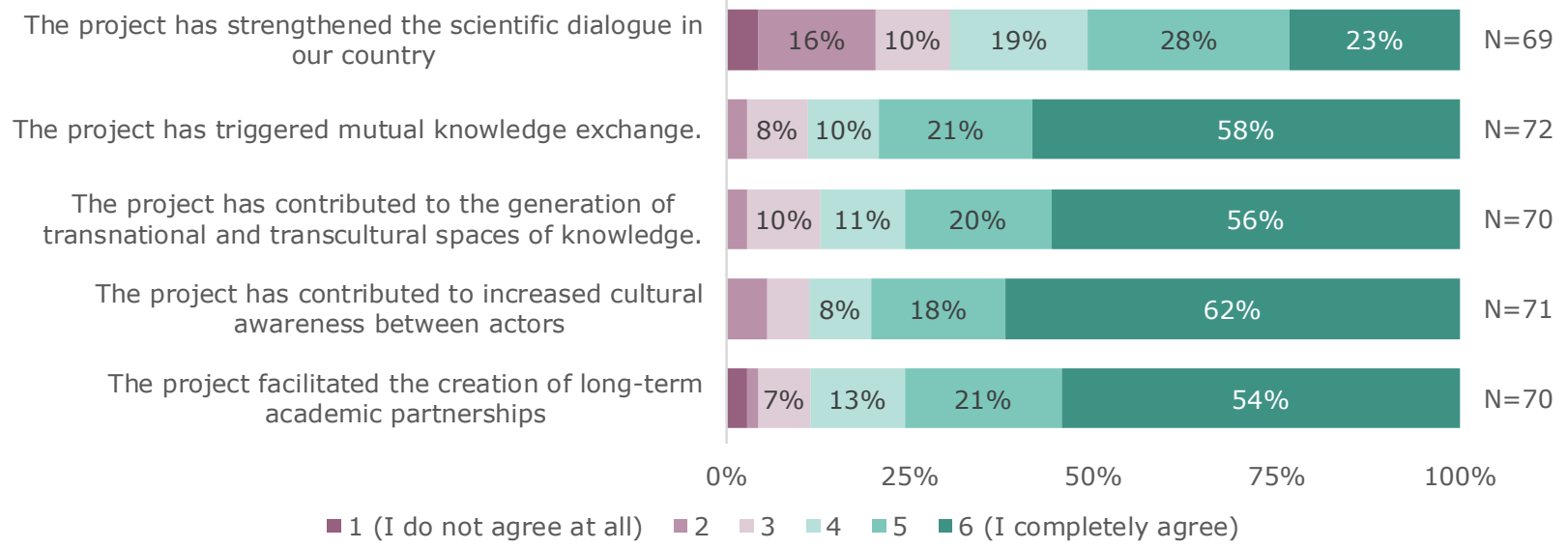

Source: CEval, 2018 (adapted by Syspons)

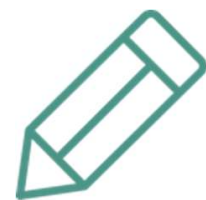

\section{Results of the APPEAR II scholarships}

In addition to the institutional partnerships, APPEAR II also funds scholarships for Master's and PhD students, which can be embedded in an APPEAR II partnership or implemented independently (stand-alone scholarships). According to the online survey data, participant institutions consider that the embedded scholarships contribute to the capacity development of partner institutions. In particular, participant institutions stated that these scholarships contributed in a positive manner to the internationalisation of their departments/organisational units. Moreover, the online survey shows that the embedded scholarships also contribute to improving the research/teaching processes and structures of the partner institutions (see Figure 20).

These findings are confirmed through the interviews, which were conducted with participant institutions. These interviews established that improvements at the organisational level can be expected when embedded scholarship holders return to and work at a university in their home countries. According to the interviews, former scholarship holders who return to their home country also bring with them enlarged networks, enhanced knowledge, newly acquired didactical skills and research methods, which they share with their colleagues at their institution. Hence, the capacities are enhanced of both former scholarship holders and also their colleagues, thereby producing structural effects at the institution in the partner country. The interviews also indicate that the stand-alone scholarships holders do not contribute to the organisational capacity of the partner institutions, but to the individual capacities of the scholarship holders. However, the stand-alone scholarships holders are likely to remain in contact with the programme and serve as a focal point for the APPEAR programme in their institutions, and they are likely to carry out APPEAR projects in the future. 


$\begin{gathered}\text { The scholarship holder(s) improve(s) the internationalization in } \\ \text { my department/organizational unit }\end{gathered}$
$\begin{gathered}\text { The scholarship holder(s) improve(s) the research processes in } \\ \text { my department/organizational unit }\end{gathered}$
$\begin{gathered}\text { The scholarship holder(s) improve(s) the teaching processes in } \\ \text { my department/organizational unit }\end{gathered}$

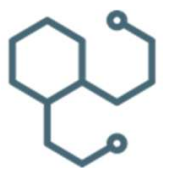

\section{Positive and negative factors that influence the achievement of APPEAR II's ob- jectives}

When analysing the achievement of APPEAR II's (intermediate) objectives, participant institutions identified positive and negative factors that influenced the achievement of the programme's objectives. In terms of the positive factors, the interviews and the online survey revealed that a good atmosphere between the participant institutions and a high degree of flexibility in the programme implementation are key. In contrast, the interviews and the online survey showed that the achievement of results is negatively affected by an instable political situation in the partner countries as well as by a complex bureaucracy in Austria (outside of the APPEAR programme, for example, regarding the visa application for the scholarship holders), in the partner countries and/or at the partner institutions. Furthermore, some project staff problems (e.g. high staff turnover and lack of motivation) also negatively influence the achievement of objectives.

\section{The implementation of APPEAR II's strategies and guiding documents}

APPEAR II follows basic principles/added values that are enshrined in a number of guiding documents for the programme. These basic principles/added values cover aspects such as gender mainstreaming, open access and disability mainstreaming. As it is important to establish to what extent these are put into practice, this section examines the implementation of APPEAR II's guiding documents. In particular, the evaluation examined to what extent the Gender Strategy, the Open Access Manual as well as the Disability Mainstreaming Manual are being implemented.

To begin with, APPEAR II has a Gender Strategy that focuses on gender mainstreaming as a fundamental principle, the systematic advancement of women, and including a gender perspective in the project, teaching and research contents (APPEAR, n.d.f). For instance, it aims at empowering women by increasing both the number of female staff in APPEAR II projects and also the number of projects that thematically work on gender issues. However, APPEAR II's Gender Strategy does not aim to mainstream gender at the university level since it focuses on the APPEAR II programme and project level (APPEAR, n.d.f). Therefore, the Gender Strategy does not focus on structural and procedural obstacles to women's advancement within the higher education sector. In terms of implementing the Gender Strategy, the online strategy reveals that participant institutions deal with gender in their academic work. The Gender Strategy therefore influences the thematic foci of the project with $61 \%$ of the projects having a topic related to gender. Additionally, the interviews specify that APPEAR II projects aim at 
focusing on female 'quotas' in the project teams, which corresponds with one of the Gender Strategy's aims of increasing the number of female staff in the projects.

Furthermore, APPEAR II has committed itself to open access and has codified this approach in the programme's Open Access Manual. Consequently, APPEAR II requires all funded projects to provide free access to scientific publications published as a result of APPEAR II-funded projects or their findings (APPEAR, n.d.i). According to the online survey, the majority (see Figure 21) of project partners indeed provide free access to their publications. This trend is also confirmed by the interviews.

Figure 21: Implementation levels of APPEAR II's Open Access Manual and Disability Mainstreaming Manual

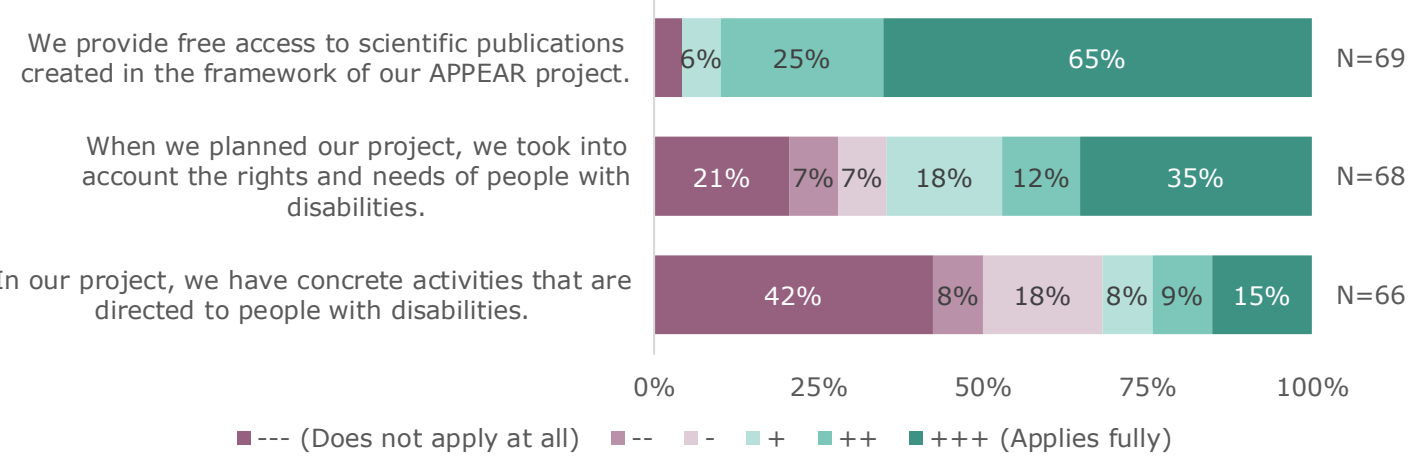

Source: Syspons, 2019

APPEAR II also has its own Disability Mainstreaming Manual whose aim is to incorporate a disability perspective, raise awareness, increase accessibility and include disability in the management of APPEAR II projects (APPEAR, n.d.e). In terms of actual implementation of the manual, the online survey indicates that it has been implemented in part. Some participant institutions took the rights and needs of people with disabilities into account when planning their project, and a few participant institutions included concrete activities in their projects that were directed at people with disabilities (see Figure 21 above). The interviews confirmed these findings as the interviewees stated that they found it difficult to accommodate the rights and needs of people with disabilities in their projects. For instance, one participant institution implementing a research project on animal breeding techniques considered it impractical to include the rights and needs of people with disabilities within its research.

\section{APPEAR II's unique features}

On the basis of the data collected as part of this evaluation, it can be observed that the APPEAR II programme has three unique characteristics.

- Firstly, the role of institutions in the partner countries is central to APPEAR II, which allows for cooperation between Austrian and partner institutions to take place on a level playing field. At least $50 \%$ of the funds must be spent in the partner countries, and the overall coordination of the project can be done by the institutions in the partner countries.

- Secondly, APPEAR II is unique by officially taking into consideration the rights and needs of people with disabilities as codified in its Disability Mainstreaming Manual. However, this manual is mainly reflected conceptually in the projects' design, but not in its implementation.

- Thirdly, the programme's open access approach is a unique feature of APPEAR II as it is mandatory for participant institutions to make any project-related publications available to the general public. 


\subsubsection{Effectiveness assessment}

The evaluation team concludes, that APPEAR II is effective, even if there is potential to further improve the programme's effectiveness. APPEAR II achieves its (intermediate) objectives, especially with regard to improving dialog and cooperation between participant institutions as well as the teaching and research quality at the participant institutions. However, APPEAR II's effects on the visibility of development research issues among the wider Austrian academic/scientific public can be further improved, as the current visibility is predominantly limited to the APPEAR II community.

Moreover, organisational capacities are mainly strengthened in terms of human capacities within the (research) project management of the APPEAR II projects. Hence, there is future potential to improve APPEAR II's results if the programme can improve processes and structures of the participant institutions. This is desirable, as such capacity building would strengthen participant institutions' capacities beyond their APPEAR II projects. In addition, embedded scholarships contribute to the capacity development of the partner universities, while the stand-alone scholarships contribute primarily to the individual capacity of the scholarship holders.

Furthermore, the evaluation team concludes that APPEAR II's strategies and guiding documents are being partially implemented. As for the implementation of the Gender Strategy, a large number of women participates in the APPEAR II projects and gender features in many research topics of the projects. However, gender mainstreaming at the university level is not the focus of the Gender Strategy and therefore no effects can be expected in this regard. However, there is potential for amending the Gender Strategy in order to achieve additional results at the university level, both at the Austrian and partner institutions. This would produce stronger structural and procedural mainstreaming effects at these institutions. The Open Access Manual is implemented to a large extent since this is not an added value but a basic principle of obligatory compliance. This is a very positive effect, as open access to the research results enhances access to this newly generated knowledge. In contrast, there is room for enhancing the implementation of the Disability Mainstreaming Manual, since this manual is partially reflected in the projects' design but not in their implementation. This means that even if the right and needs of persons with disabilities are considered while planning the projects, these are not being considered when implementing the projects.

Lastly, APPEAR II is unique because APPEAR partnerships take place on a level playing field, which leads to the partner institutions playing a very valuable role. This is due to APPEAR's demand-driven and bottom-up approach. Furthermore, the conceptual approach of APPEAR II's disability manual is progressive regarding the consideration of needs and rights of persons with disabilities. However, this positive characteristic of the programme design still needs to be implemented by the APPEAR projects. Finally, APPEAR II's design is unique since it has an Open Access policy, which means that the knowledge created within the projects is shared with the public in general. This allow other stakeholders to use this knowledge in the future. 


\section{Conclusions}

The evaluation team concludes that APPEAR II is doing the right thing. In this vein, APPEAR II is highly relevant both at the international and Austrian level since it is aligned with the international and Austrian frameworks/strategies in the area of (scientific) cooperation in development. When analysing the relevance of the programme's added values, the evaluation team concludes that APPEAR II is a pioneer in the area of cooperation in the tertiary education sector, since its projects should be aligned with the respective ADC country strategies, and the rights and needs of persons with disabilities should be considered in the APPEAR projects. The relevance of the programme could however be further improved by expanding the concept of "marginalized groups" ("leave no one behind" in the Agenda 2030), since this concept is currently limited to persons with disabilities and women.

Furthermore, the relevance of the programme at the Austrian level can be further improved if the ADC local offices harmonise different ADC programmes with APPEAR II projects in the partner countries in order to maximise the results of the ADC. In addition, it was observed that the programme focuses on achieving the SGDs in the partner countries. The programme does not concentrate on achieving the SGDs in Austria, the role of the Austrian participant institutions is therefore unclear in terms of contributing to this achievement.

Moreover, the evaluation team considers that APPEAR II and the other initiatives of the ADA portfolio in the area higher education/research are coherent and complementary. Thus, there is no significant overlap with the initiatives in the aforementioned portfolio.

Furthermore, the evaluation team concludes that the programme design and approach enable an efficient programme implementation. Both partner organisations and scholarship holders are highly satisfied with the manner in which APPEAR II is being implemented. When analysing the first component in particular, the evaluation team concludes that a duration of up tp four years is ideal in order to carry out the Academic Partnerships. This minimum duration takes into account the fact that at the beginning of the projects, the participant institutions need time to get to know their partners and established foundations for the partnership. Moreover, there is potential to improve the programme's efficiency since a results-oriented monitoring system could replace the current monitoring system that focuses on the activity level.

Moreover, it is concluded that APPEAR II focus on improving the organisational capacities of the participant institutions, while the stand-alone scholarships focus on improving the individual capacities of the scholarship holders. However, it was observed that the stand-alone scholarship holders have an important function, when it comes to recruit new partners for APPEAR. Therefore, there is a need to integrate them better in the APPEAR programme.

The highly efficient implementation of the programme is due to the fact that the OeAD uses its vast expertise both in the area of development cooperation in the tertiary education sector as well as programme implementation. Nevertheless, the programme's efficiency can be further improved by connecting universities with little or no international experience with potential partners so that they can jointly develop and implement APPEAR projects. This facilitation is currently being offered by the OeAD but it is not being used by the academic/research institutions in a systematic manner, since not all institutions are aware of this service.

Moreover, the programme design and approach enable an effective programme implementation. In this regard, the programme design has three mechanisms that assure that the programme's outputs and outcomes are developmentally relevant for the partner countries and for their institutions. These three mechanisms assure that APPEAR II is capable of contributing in the long run to the achievement of the SDGs: i) the Preparatory Funding; ii) the application forms for Academic Partnerships and Advanced Partnerships; and iii) relevance assessment of the ADC local offices in the selection process. 
Furthermore, the evaluation team concludes that APPEAR II is effective in reaching its (intermediate) objectives. However, there is potential to improve the programme's effectiveness. With regard to the aspects that do work effectively, APPEAR II strongly improves the teaching and research capacities of the participant institutions as well as the dialogue and cooperation between the participant institutions.

However, the effectiveness of APPEAR II can be further improved regarding the visibility of development research issues among the wider Austrian academic/scientific public, since the visibility is so far mainly improved within the APPEAR II community. Similarly, APPEAR II can further increase its effectiveness by improving to a larger extent the processes and structures of the participant institutions. This is important as such structural capacity building would strengthen the partner institutions beyond the APPEAR II projects and would therefore contribute to the sustainability of the programme's effects. Moreover, APPEAR II's embedded scholarships strongly contribute to the capacity development of partner institutions through internationalisation and knowledge sharing, while the stand-alone scholarships contribute to the individual capacities of the scholarship holders.

With regard to APPEAR II's guiding documents, these are being partially implemented. The Open Access Manual's implementation is strong, which is due to its mandatory nature. Similarly, the gender mainstreaming of APPEAR II is strong because, for instance, the number of women participating in the projects is being increased, one of the aims of the Gender Strategy. However, the Gender Strategy could be broadened to also aim at improvements at the university level. Furthermore, APPEAR II is pioneering for considering the rights and needs of people with disabilities. However, the implementation of the Disability Mainstreaming Manual is limited to the projects' design and is not reflected in the implementation of APPEAR II projects.

Finally, there are three unique features of the APPEAR II programme, namely: i) the valuable role of partner institutions, which allows the partnership to take place on a level playing field; ii) conceptually taking into account the rights and needs of people with disabilities, despite its implementation gap; and iii) the open access requirement. 


\section{Recommendations}

The evaluation results show that APPEAR II is highly relevant, and that its design and approach are efficient and effective. The results also reveal potential for further development. To make use of this potential, the evaluation team derived the subsequent seven recommendations.

1. The APPEAR programme should be continued as it is highly relevant, efficient and effective. In APPEAR's third phase, the programme design and approach should maintain the instruments and mechanisms that have proved supportive of the programme's smooth implementation and its effectiveness. Furthermore, APPEAR's added values should be strengthened in order to further increase the programme's relevance.

The evaluation results show that APPEAR II is highly relevant and effective. In order to maintain the programme's relevance and effectiveness, the evaluation team recommends the further implementation of the basic principles and added values. In particular, the programme's focus on development research should be maintained. Furthermore, regarding the implementation of the added values, the evaluation team recommends expanding the concept of "marginalized groups". This concept is currently limited to persons with disabilities and women. In order to increase the programme's relevance, this concept should also include other marginalised and disadvantaged groups in the light of Agenda 2030's "Leave No-one Behind" principle.

Furthermore, the evaluation results indicate that the programme is being implemented in an efficient and flexible manner and the evaluation team recommends that this should continue. In this regard, the Preparatory Funding has proved to be successful since it helps to identify partnerships that are likely to function in a constructive manner, and because it allows for joint planning of the APPEAR projects.

However, in order to increase the programme's efficiency even more, the maximum project duration should be extended to up to four years for Academic Partnerships. With an extended project duration, the programme can ensure that the participant institutions have enough time to set solid foundations for cooperation and carry out the project in a way that corresponds to the implementation rhythm of the participant institutions. For Advanced Academic Partnerships, a minimal duration of two or three years is recommended.

2. In order to further improve the relevance and effectiveness of the programme, one or two new instruments should be added to the first component. These instruments should aim at improving the programme's contribution to the organisational capacities of participant institutions (processes and structures) and/or the research uptake.

The evaluation results show that APPEAR II is highly relevant and effective. However, this can be further improved by supporting partnerships that focus on improving the organisational processes and structures of the participant institutions and/or that focus on research uptake. Thus, the evaluation team recommend the addition of one or two new instruments to the first component. In order to use the new instruments, an Academic Partnership needs to have been previously implemented. Since the partners will have already carried out a joint project, the basis for cooperation is already set and therefore the duration of the new instrument(s) should be between two and three years. However, it should be possible to add new actors to the partnerships if the proposed APPEAR project requires the know-how of other stakeholder(s). In this vein, it should also be possible for different APPEAR projects within the same university/ies to come together and generate broader partnerships in order to generate synergies for the partner institution. Furthermore, these new instruments, in the following text referred to as "Expert Partnerships", should maintain the flexibility that characterizes APPEAR II, so that the participant institutions are able to develop projects that correspond to their own needs and the needs of their countries. 
In this vein, the evaluation team has developed the following scenarios:

\section{Scenario 1: A new instrument should be added to the first component in order to support "Expert institutional partnerships".}

The "Expert institutional partnerships" should focus on achieving results beyond the APPEAR projects and therefore on the processes and structures of the participant institutions. These partnerships should concentrate on improvements at the faculty and institute level, since this is the level that project coordinators and project staff can influence. This new instrument should primarily address teaching and research processes and structures.

\section{Scenario 2: A new instrument should be added to the first component in order to support "Expert applied partnerships".}

The "Expert applied partnerships" should focus on research uptake. This means that research results previously generated in an APPEAR project should be disseminated to relevant stakeholders (for instance, NGOs, private sector actors, international agencies, civil servants, legislators and political parties, intermediaries, the media and local communities). This way, the research results can be implemented and used for the programme to contribute more to achieving the SGDs.

\section{Scenario 3: Two new instruments should be added to the first component in order to support "Expert institutional partnerships" and "Expert applied partnerships".}

If the responsible organisations consider it strategic to improve the programme's effects regarding both the organisational capacities of the participant institutions as well as research uptake, APPEAR should implement the two aforementioned new instruments.

3. The evaluation results show that the stand-alone scholarships contribute to the individual capacity of the scholarship holders, while APPEAR II focuses on contributing to the capacity development of the participant institutions. In order to improve the programme's coherence, it is recommended to reduce the gap between the stand-alone scholarships and the programme's rationale.

The evaluation team concludes that APPEAR II focuses on improving the organisational capacities of the participant institutions, while the stand-alone scholarships focus on improving the individual capacities of the scholarship holders. Nevertheless, the stand-alone scholarship holders have a central function regarding the recruitment of new partners for APPEAR. Therefore, there is a need to integrate these scholarships better in the APPEAR programme.

In this vein, the stand-alone scholarship holders should be APPEAR ambassadors. For this purpose, three concrete measures are recommended. Firstly, the programme should offer stand-alone scholarship holders a course in project management skills that emphasises the management of APPEAR projects. Secondly, the stand-alone scholarship holders should be asked to submit an application for an Academic Partnership once they finish their studies. Thirdly, APPEAR should carry out networking events for the scholarship holders to expand their networks and find potential partners for their APPEAR application(s).

4. In order to improve APPEAR's effectiveness, the programme monitoring system (first and second component) should be further developed into a results-oriented monitoring system.

The evaluation results show that the programme's monitoring system functions at the activity level. This means that the OeAD reports the relevant activities from a given period of time to the ADA. This type of monitoring does not allow ADA and the FMEIA to know the actual status regarding achievement 
of the programme's objectives. Therefore, APPEAR's monitoring system should evolve from the activity level to the outcome level (see the Theory of Change). For this, indicators should be developed for each of the programme's outcomes.

Regarding the scholarships (second component), a tracer study should take place in order to analyse whether the scholarship holders (both from embedded and stand-alone scholarships) return to their institutions in the partner countries or not. This would allow for an analysis of whether an improvement in the individual capacities of the scholarship holders produces an improvement in the organisational capacities of the participant institutions.

\section{APPEAR's public relations should be further developed in order for the programme to expand its} target group and to further promote the achievement of the SDGs.

The evaluation results show that APPEAR II's public relations are being implemented in an efficient manner and that they are widely accepted by the participant institutions. Nevertheless, the programme's public relations can be further improved by implementing the following measures.

To begin with, academic/research institutions with little or no international experience need to get to know and connect with other institutions with whom they can design and implement APPEAR projects. Even if this facilitation service is being offered by the OeAD, it is not being systematically used by the academic/research institutions, since many of them are not aware of it. In this regard, APPEAR should take a strategic decision on whether this service should be publicized in a broader manner so that more institutions make use of it. In this case, additional resources should be dedicated to carrying out this facilitation since institutions with little or no international experience will require stronger support from the APPEAR office during project planning and implementation.

Furthermore, APPEAR II has contributed to an improved visibility of development research issues among the participant institutions. However, this improvement has been limited to the APPEAR II community and has not yet reached the wider Austrian academic/scientific public. In order to reach other academic/scientific relevant stakeholders, the implementing organisation should expand its current networks; e.g. by taking part in the network Alliance of Sustainable Universities in Austria.

Moreover, the evaluation results show that APPEAR II contributes to the achievement of the SDGs both in the partner countries and in Austria. However, it focuses on its contribution in the partner countries. In keeping with the programme's rationale, the programme should not be focused on achieving the SDGs in Austria. However, where synergies are possible within the projects which effectively contribute to the SDGs in Austria, these should be implemented. This should be communicated to the participant institutions so that they are aware of the programme's desire to achieve these synergies.

6. In order for APPEAR to counteract the structural and procedural obstacles to women's advancement within the higher education sector, the programme's Gender Strategy should be revised and updated.

The programme has a Gender Strategy which is being implemented in the framework of APPEAR II projects. The evaluation results show that the implementation of the Gender Strategy influences predominantly the thematic foci of the projects and ensures female 'quotas' in the project teams. However, state-of-the-art gender discussion indicates that structures and processes in the workplace should be modified in order to counteract gender inequalities. For example, when female scientists do not participate in the decision-making processes in their faculties, they cannot advance in their scientific careers in a similar manner to men.

In this vein, APPEAR should take its Gender Strategy to the next level in order to influence in a positive manner: 
- the processes and structures within the APPEAR projects: for this purpose, the APPEAR forms (in particular those used to submit applications) should be adjusted once the Gender Strategy is revised and updated.

- the processes and structures in the departments/institutes in which the project coordinators/project staff work: in this regard, the programme should use the proposed instrument "Expert institutional partnerships" (see second recommendation).

7. In order to increase the programme's relevance, the creation of synergies is recommended between APPEAR and other ADA programmes. In this vein, analysis and discussion should focus on the extent to which the ADC local offices should connect APPEAR projects with other ADC programmes in the different partner countries.

According to the evaluation results, APPEAR II is highly relevant at the Austrian level. Nevertheless, this relevance can be further improved if the ADC local offices are able to connect the results of APPEAR projects with other ADA programmes in the target countries. In order to generate those synergies, the data management (systems) and information flows within the APPEAR programme should be improved. This would allow the ADC offices to have an overview of the APPEAR projects (for instance, access to the projects' key data) and their status regarding achievement of their goals.

In case it is decided that the ADC local offices should actively aim at achieving these synergies, it should be examined whether it is possible to increase the resources allocated to the ADC offices in order for them to carry out this function. 
SYS

PON S 